\title{
CALIBRATION MEASUREMENTS OF CONTROL AND SAFETY RODS IN THE ENRICO FERMI REACTOR
}

\author{
R. E. Mueller \\ C. E. Branyan
}




\section{DISCLAIMER}

This report was prepared as an account of work sponsored by an agency of the United States Government. Neither the United States Government nor any agency Thereof, nor any of their employees, makes any warranty, express or implied, or assumes any legal liability or responsibility for the accuracy, completeness, or usefulness of any information, apparatus, product, or process disclosed, or represents that its use would not infringe privately owned rights. Reference herein to any specific commercial product, process, or service by trade name, trademark, manufacturer, or otherwise does not necessarily constitute or imply its endorsement, recommendation, or favoring by the United States Government or any agency thereof. The views and opinions of authors expressed herein do not necessarily state or reflect those of the United States Government or any agency thereof. 


\section{DISCLAIMER}

Portions of this document may be illegible in electronic image products. Images are produced from the best available original document. 

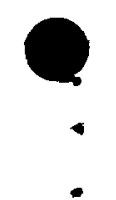


\section{ABSTRACT}

This report describes the control and safety rod calibration measurements made during the low-power testing of the Enrico Fermi reactor. These measurements were made to confirm the rod design and also to investigate different calibration techniques.

Accurate calibrations were obtained over the full length of rod travel for various degrees of shadowing by adjacent rods. Positive period, negative period, subcritical count rate, and intercalibration techniques are described. The results are compared with critical experiment data. Means by which the calibration procedure could be improved are discussed. 
?

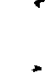

.

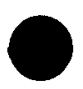

$\checkmark$ 


\section{FOREWORD}

This is one of a series of reports on the low-power (up to $1 \mathrm{Mwt}$ ) and high-power (up to $200 \mathrm{Mwt}$ ) nuclear testing of the Enrico Fermi fast breeder reactor. The Nuclear Test Program is planned, directed, and evaluated by Atomic Power Development Associates, Inc. (APDA). The tests are conducted by Power Reactor Development Company (PRDC). The reactor proper is owned and operated by PRDC. The steam generators and electrical generating facilities are owned by The Detroit Edison Company (DECo).

Many individuals have contributed to the nuclear testing of the Fermi reactor. Listed below are those, exclusive of the authors, who have made significant contributions to the work reported in this document.

Experimenta1 Phases
D. A. Erdman
PRDC *
G. C. Tyson
PRDC
A. D. Smart
$\mathrm{DEC} O$

Analytical Phases
C. R. Moore
APDA $\dagger$
C. S. Yeh
APDA

Planning and Testing

$\begin{array}{ll}\text { J. B. Nims } & \text { APDA } \\ \text { E. L. Alexanderson } & \text { PRDC }\end{array}$

* On leave from Potamic Electric Co., Washington, D. C.

$\dagger$ Presently with Nuclear Fuel Services, Inc., Wheaton, Maryland 
$\bullet$

. 
Page

LIST OF ILLUSTRATIONS $\ldots \ldots \ldots \ldots \ldots \ldots \ldots \ldots \ldots \ldots \ldots \ldots \ldots$

LIST OF TABLES $\ldots \ldots \ldots \ldots \ldots \ldots \ldots \ldots \ldots \ldots \ldots \ldots \ldots$

SUMMARY $\ldots \ldots \ldots \ldots \ldots \ldots \ldots \ldots \ldots \ldots \ldots \ldots \ldots \ldots \ldots \ldots \ldots \ldots \ldots \ldots$

I. PURPOSE OF $\mathrm{TEST} \ldots \ldots \ldots \ldots \ldots \ldots \ldots \ldots \ldots \ldots \ldots$

II. DESCRIPTION OF THE ENRICO FERMI REACTOR $\ldots \ldots \ldots \ldots$

A. GENERAL DESCRIPTION .................. 3

B. CONTROL AND SAFETY RODS ................ 6

1. Control Rods .......................... 8

2. Safety Rods ........................ 10

III. EXPERIMENTAL PROCEDURE $\ldots \ldots \ldots \ldots \ldots \ldots \ldots \ldots \ldots$

A. DESCRIPTION OF THE TEST ................. 13

1. Control Rod Calibration .................. 13

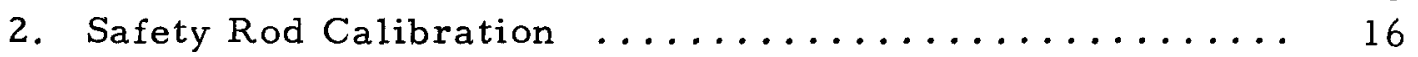

B. REACTOR PLANT CONDITIONS ................ 20

C. NEUTRON SOURCE AND INSTRUMENTATION ......... 22

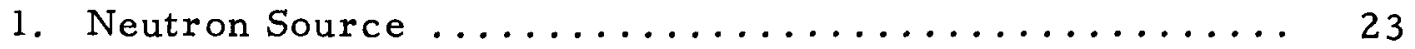

2. Instrumentation ...................... 23

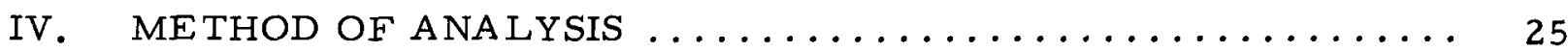

A. PERIOD CALIBRATION MEASUREMENTS .......... 25

B. SUBCRITICAL COUNT RATE CALIBRATION

MEASUREMENTS .................... 26

C. INTERCALIBRA TION MEASUREMENTS ........... 28

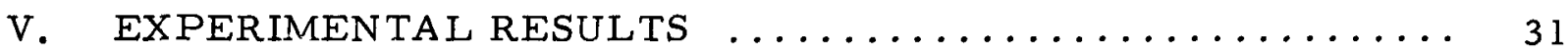

A. CONTROL ROD CALIBRATIONS ............... 31

1. Regulating Rod Calibration ................. 31

2. Shim Rod Calibration ................... 36

B. SAFETY ROD CALIBRATION ................ 38

1. Calibration of Individual Rods ............... 38

2. Ganged Calibration .................. 45

VI. CONCLUSIONS AND RECOMMENDA TIONS $\ldots \ldots \ldots \ldots \ldots \ldots$

REFERENCES $\ldots \ldots \ldots \ldots \ldots \ldots \ldots \ldots \ldots \ldots \ldots \ldots \ldots \ldots \ldots \ldots \ldots$ 
•

. 


\section{LIST OF ILLUSTRA TIONS}

Figure

Title

$\underline{\text { Page }}$

1. Perspective View of Reactor $\ldots \ldots \ldots \ldots \ldots \ldots \ldots \ldots \ldots$

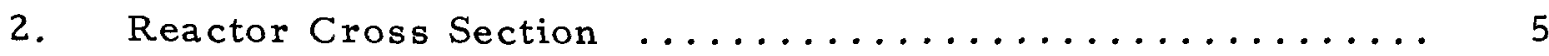

3. Operating Control and Safety Rod Positions in Reactor Vessel ......................... 7

4. Operating Control Rod $\ldots \ldots \ldots \ldots \ldots \ldots \ldots \ldots \ldots \ldots, 9$

5. Safety Rod Assembly ....................... 11

6. Initial Core Loading for Rod Calibration Measurements .... 17

7. Regulating Rod Calibration Curves $\ldots \ldots \ldots \ldots \ldots \ldots \ldots . \ldots . \ldots . \ldots$

8. Shim Rod Calibration Curves $\ldots \ldots \ldots \ldots \ldots \ldots \ldots \ldots . \ldots \ldots$

9. Calibration of No. 1 Safety Rod $\ldots \ldots \ldots \ldots \ldots \ldots \ldots . \ldots . \ldots . \ldots$

10. Calibration of No. 2 Safety Rod $\ldots \ldots \ldots \ldots \ldots \ldots \ldots, 40$

11. Calibration of No. 4 Safety Rod $\ldots \ldots \ldots \ldots \ldots \ldots \ldots, 41$

12. Ganged Safety Rod Calibration $\ldots \ldots \ldots \ldots \ldots \ldots \ldots \ldots, 46$

\section{LIST OF TABLES}

Table

$\underline{\text { Title }}$

$\underline{\text { Page }}$

1. Subassembly Additions and Excess Reactivities of Loadings .. 21

2. Regulating Rod Calibration $\ldots \ldots \ldots \ldots \ldots \ldots \ldots \ldots \ldots, 32$

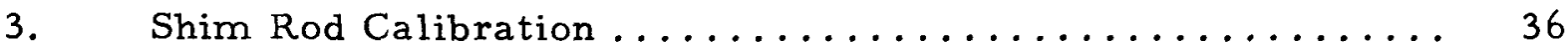

4. Safety Rod Calibrations $\ldots \ldots \ldots \ldots \ldots \ldots \ldots \ldots \ldots \ldots \ldots \ldots \ldots \ldots \ldots$ 
$\bullet$

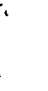

.

. 


\section{SUMMARY}

During the low-power testing of the Enrico Fermi reactor, detailed calibration measurements of the control and safety rods were made to confirm the rod design and also to investigate the adaptability of different calibration techniques. Worths of individual unshadowed and shadowed rods were obtained as well as ganged rod worth. The measured rod worths were approximately 6 to 15 per cent less than had been originally predicted from ZPR-III critical experiment data. This agreement is considered satisfactory in view of design changes which have been made since the time of the critical experiment.

The control rod calibrations were made in the period October 24, 1963, through November 1, 1963. The safety rod calibration measurements were made November 4, 1963, through November 8, 1963. The tests were conducted approximately two months after initial criticality of the reactor. Because of the nuclear and mechanical design of the rods, several calibration methods were required to obtain complete calibrations. The techniques used were positive period, negative period, and subcritical count rate measurements, together with intercalibration measurements between rods. The following data were obtained:

- The worth of the regulating control rod as a function of position for a wide range of shadowing conditions caused by the adjacent shim rod

- The shim rod worth as a function of position for the fully-shadowed and fully-unshadowed conditions

- Safety rod worth as a function of position, for each of three typical safety rods, both fully shadowed and fully unshadowed

- The ganged worth calibration for the simultaneous withdrawal of the seven installed safety rods

The worths found for the fully-unshadowed shim and regulating rods were 47.5 cents and 44.8 cents, respectively; the predicted value was 47.9 cents for each rod. The worths of the fully-shadowed shim and regulating rods were 46.0 cents and 43.7 cents, respectively; the predicted value was 46.4 cents. Thus, the measured shim rod worths were about 1 per cent less than predicted, whereas the regulating rod worths were, on the average, approximately 6 per cent less than predicted. The difference in worth measured for the identical control rods can be attributed to the perturbation of a retractable neutron source which was located in the core near the shim rod during the test. 
Similar agreement between measured and predicted worths was obtained in the safety rod calibrations. The measured unshadowed worths of the three typical safety rods in the lattice ranged from 1.22 to 1.46 dollars, with a 20 per cent shadowing effect; the ganged worth of the seven rods withdrawn together was found to be approximately 8.07 dollars. The measured safety rod worths were, on the average, about 15 per cent less than predicted. 


\section{PURPOSE OF TEST}

Control rod measurements were made to obtain accurate calibration of the reactivity worths of the shim and regulating rods, as a function of position, for various degrees of shadowing. These data were needed so that accurate static reactivity measurements could be made later on in the Nuclear Test Program. Control rod preliminary calibrations had been obtained earlier in the low-power test program 1,2 , but these did not include shadowing effects. Therefore, they were considered inadequate for accurate test measurements.

The original purpose of the safety rod calibration measurements was to obtain the total reactivity worth as a function of position of: (1) each individual safety rod under unshadowed conditions, (2) the three typical rods in the lattice under shadowed conditions and, (3) the ganged safety rods during the simultaneous withdrawal of all seven installed rods. However, the unshadowed worths of the first three typical rods tested were in close agreement with the results obtained for these rods in earlier tests by other methods. ${ }^{2}, 3$ Therefore, the calibrations were abbreviated to include individual calibrations of only the three typical rods (shadowed and unshadowed), and the ganged worth.

The unshadowed worths of the individual safety rods were needed to confirm the design calculations of rod worth. The design specifications were that each unshadowed rod should have a negative reactivity worth of one dollar or more. This is important from the viewpoint of reactor safety. It was possible to predict the net worth for ganged insertion or withdrawal from the individual rod shadowed data. The ganged safety rod calibration was needed to establish accurately the two subcritical stop points located near the end of the rod travel and used for prediction of criticality. Count rates taken at these points are used to predict the degree of subcriticality with the safety rods fully withdrawn. This is important in meeting the operating requirement that criticality not be achieved during withdrawal of the safety rods. 
-

.

.

. 


\section{DESCRIPTION OF THE ENRICO FERMI REACTOR}

\section{A. GENERAL DESCRIPTION}

The Enrico Fermi reactor and its associated structures are shown in perspective in Fig. 1. The reactor is contained in a stainless steel reactor vessel sealed at the top by a rotating shield plug which supports the control mechanisms, the holddown mechanism and the fuel handling mechanism. The reactor vessel is surrounded by borated and plain graphite neutron shielding material which is contained inside the primary shield tank. The reactor is of the fast-breeder type, cooled by sodium, and operated at essentially atmospheric pressure. The maximum reactor power with the first core loading (Core A) is $200 \mathrm{Mwt}$.

The core and blanket, located in the lower reactor vessel, consist of square subassemblies containing the fuel pins and blanket rods arranged to approximate a cylinder about $80 \mathrm{in.}$ in diam and $70 \mathrm{in.} \mathrm{high.} \mathrm{The} \mathrm{core,}$ contained in the central portion of the core subassemblies, approximates a right cylinder 31 in. in diam and $31 \mathrm{in.} \mathrm{high;} \mathrm{it} \mathrm{is} \mathrm{axially} \mathrm{and} \mathrm{radially}$ surrounded by breeder blankets. The fuel in Core A consists of zirconiumclad pins containing $\mathrm{U}-10 \mathrm{w} / 0$ molybdenum alloy with the uranium enriched to $25.6 \mathrm{w} / 0 \mathrm{U}-235$. Each fuel subassembly in the core contains 140 fuel pins having a total mass of approximately $4.75 \mathrm{~kg}$ of U-235 per subassembly. The blanket is depleted U-3 w/o molybdenum alloy.

The reactor cross section, shown in Fig. 2, indicates the placement of individual components within the lower reactor vessel. There is a total of 149 central lattice positions that are occupied by core and inner radial blanket subassemblies, the neutron source, and the 10 operating control and safety rod channels. These positions are supplied with sodium coolant flowing upward from a high-pressure plenum which is connected to the discharge lines of the three primary sodium pumps. The coolant flows upward through the individual core and inner radial blanket subassemblies into a large upper plenum and from there by gravity to the three intermediate heat exchangers and then to the suction side of the primary pumps. Sodium also is used in the secondary cooling system.

The lattice positions surrounding the inner radial blanket comprise the outer blanket area; when filled with outer radial blanket subassemblies, they form an annular region whose top and bottom are at the same elevation as the top and bottom of the inner radial blanket. Surrounding the outer radial blanket are lattice positions for stainless steel subassemblies which provide thermal and neutron shielding. The outer radial blanket and shielding lattice positions are supplied with sodium coolant from the low-pressure 


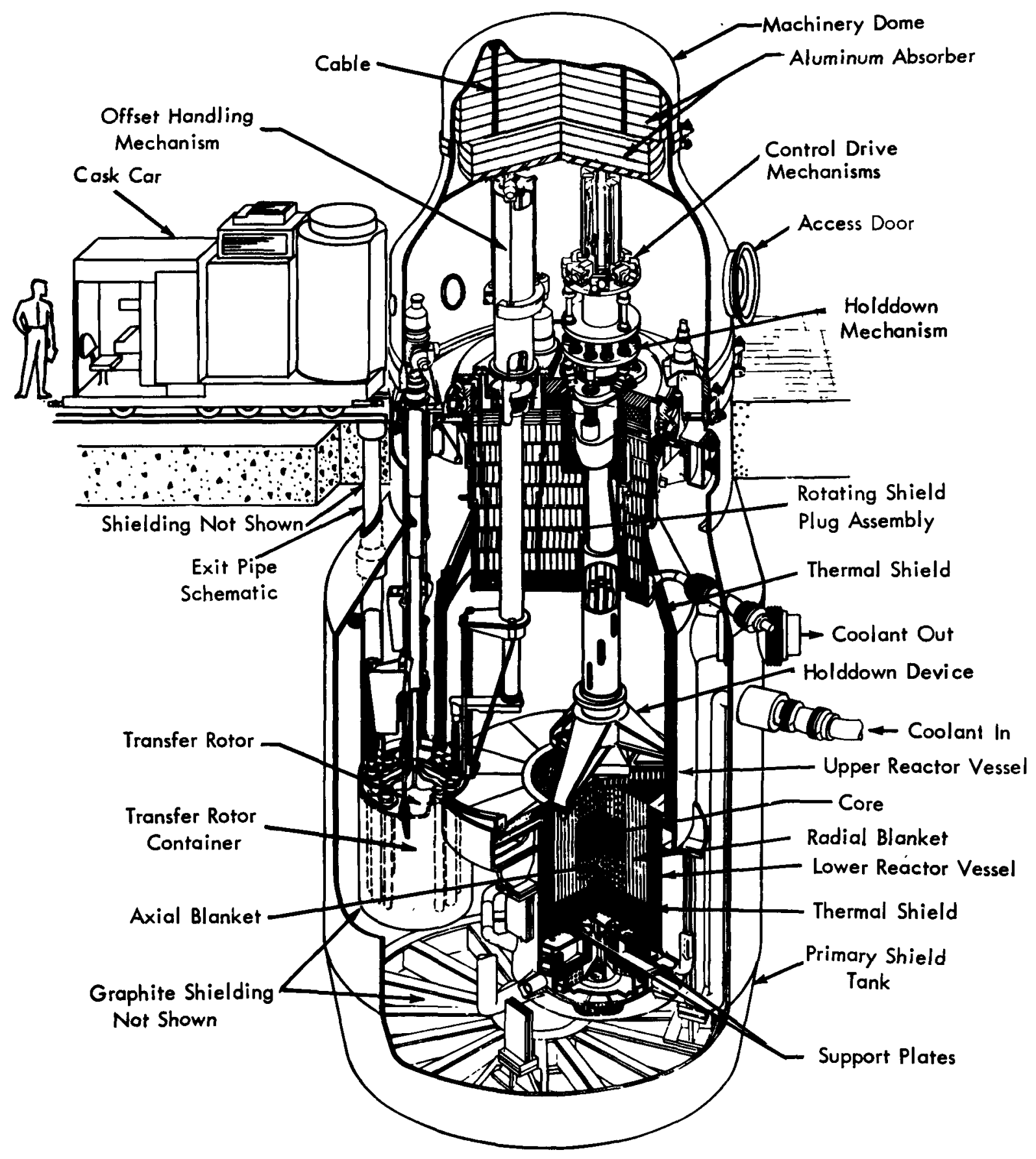

FIG. I PERSPECTIVE VIEW OF REACTOR 


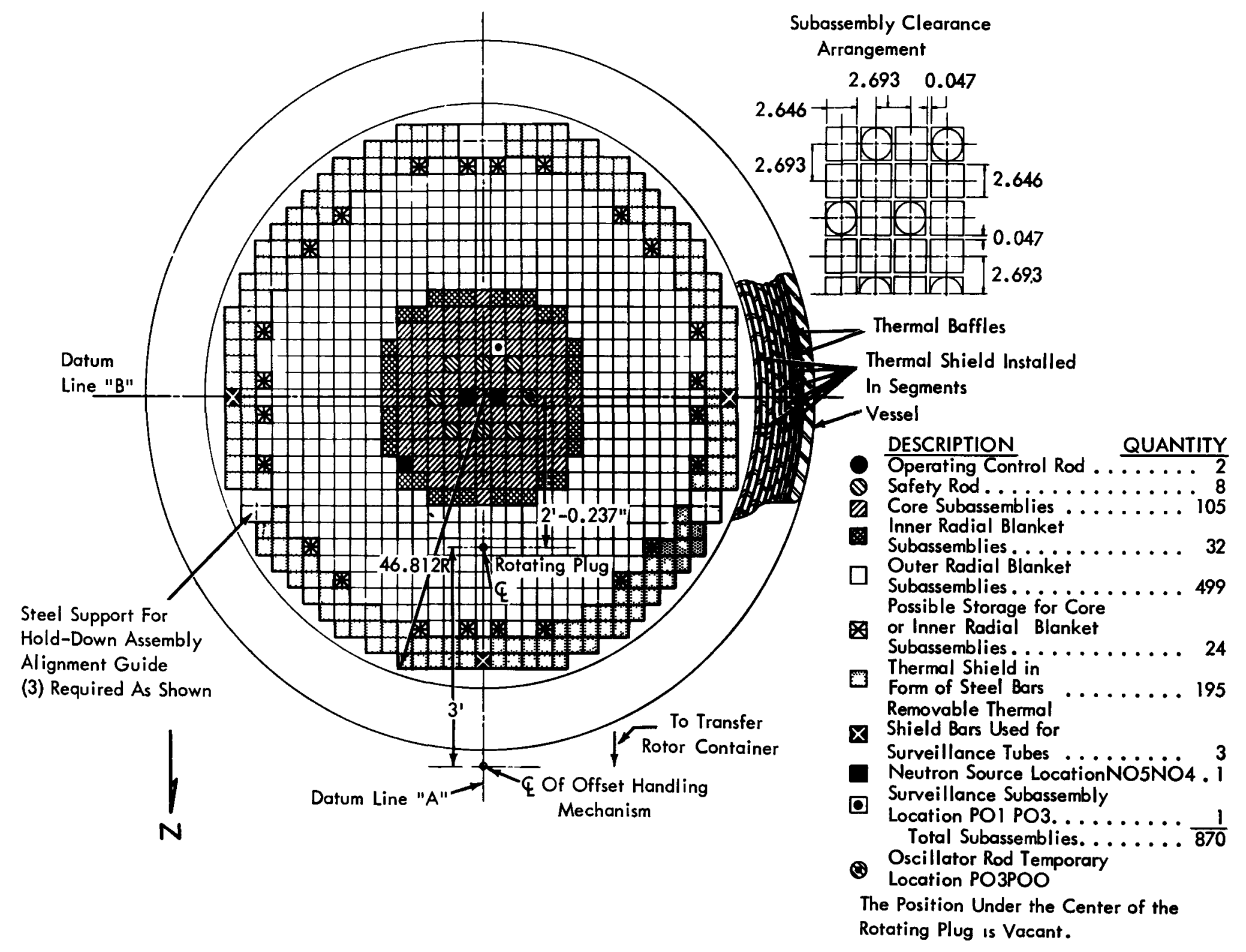

FIG. 2 REACTOR CROSS SECTION 
plenum. The sodium from the low-pressure plenum, after cooling the blanket and thermal shield subassemblies, is mixed in the upper plenum with the sodium from the core before flowing to the intermediate heat exchangers.

The neutron detectors (fission chambers and ion chambers) for normal reactor operation at-power, are located in six neutron-counter tubes (NCT) embedded in the graphite neutron shield surrounding the reactor vessel. Eleven channels of nuclear instrumentation are distributed throughout the six neutron-counter tubes in a manner which covers the full power range during reactor operation. During the low-power testing, however, the temporary instrumentation described in Section III-C-2 was used.

A permanent antimony-beryllium ( $\mathrm{Sb}-\mathrm{Be}$ ) neutron source is normally located in the reactor at the core-blanket interface (Fig. 2) to provide a neutron flux at the neutron detectors during reactor startup and to maintain a flux when the reactor is shut down. It consists of a fixed radioactive $\mathrm{Sb}$ rod inside a beryllium can. However, during this test a temporary retractable neutron source was in use, installed in the core in the safety rod position shown occupied by the oscillator rod in Fig. 2. It permitted more accurate reactivity measurements to be made by eliminating source reactivity effects. Its design is similar to that of the permanent source, except the $\mathrm{Sb}$ rod can be retracted from the beryllium. Its design and use is explained in more detail in Section III-C -1 .

Additional information concerning the reactor design may be found in Reference 4.

\section{B. CONTROL AND SAFETY RODS}

Reactor control is normally accomplished by two operating control rods and eight safety rods. However, during this test only seven of the eight safety rods were installed, safety rod No. 5 having been removed to allow for installation of the in-core, retractable neutron source. The locations of the control and safety rods in the reactor core are shown in Figs. 2 and 3. All of the rods are of the pois on type, containing boron carbide $\left(\mathrm{B}_{4} \mathrm{C}\right)$ enriched in boron-10 (B-10). One operating control rod is for regulating purposes and the other is for shimming. The two rods have a total negative reactivity worth of about 92 cents. * The eight safety rods which are symmetrically spaced around the center of the core provide

* The reactivity conversions for the Fermi reactor are:

1 cent $=3.19$ inhours

1 inhour $=2.08 \times 10^{-5} \Delta \mathrm{k} / \mathrm{k}$

$\beta$ eff $\quad=0.00662$ 


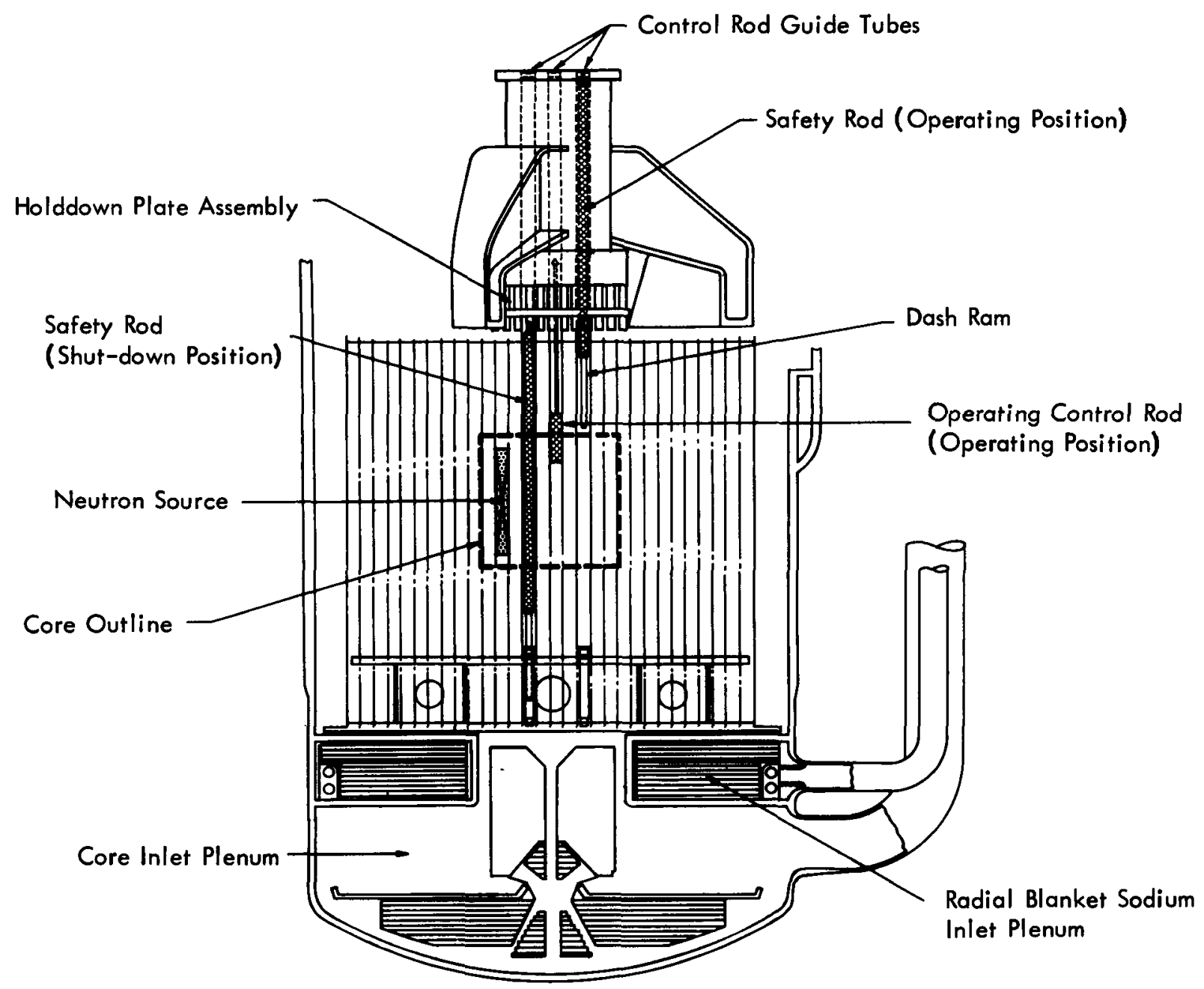

FIG.3 OPERATING CONTROL AND SAFETY ROD POSITIONS IN REACTOR VESSEL 
a total negative shutdown reactivity of approximately 9 dollars. During reactor operation, the safety rods are poised above the axial blanket section of the core subassemblies. From this position they can be rapidly inserted into the core when the reactor is scrammed. They also provide the holddown reactivity during refueling operations. The control and safety rods are actuated from the top and must be disconnected from their drive mechanisms while fuel is being loaded.

\section{Control Rods}

The two operating control rods are located on opposite sides and 2-1/2 in. from the vertical centerline of the core (Fig. 2). Each control rod is housed in a cylindrical guide tube as shown in Fig. 3. The guide tubes are divided into upper and lower sections. The upper sections are mounted permanently in the core holddown plate and column and move with them, whereas the lower guide tubes are seated in the upper and lower core-support plates. Heat generated in a control rod is removed by sodium flowing upward from the core inlet plenum.

The two operating control rods are identical in design (Fig. 4). Each rod contains $88 \mathrm{~g}$ of $\mathrm{B}-10$ in the form of 34 per cent enriched boron in $\mathrm{B}_{4} \mathrm{C}$, giving a combined worth of approximately 92 cents $(46$ cents per rod). The poison is contained in 19 hermetically sealed, stainless steel tubes. The length of the active poison section is only $10 \mathrm{in.A}$. A helium gas collection space is located in the tubes above the poison section. An extension rod connects the poison section to a pickup head which is located at the top of the rod. The pickup head connects to the control rod drive mechanism by means of rod gripper fingers which are in turn operated by a magnetic latching mechanism.

One rod, the faster moving or regulating rod, is used for startup and control, while the slower rod is used primarily as a shim rod. The average reactivity insertion rates of these rods are approximately one cent per sec and one cent per min, respectively. The operating control rods are not released and dropped into the core during a scram but are, instead, driven slowly into the core. During reactor shutdown, they are delatched from their drives and rest on a pedestal or seat located in the lower guide tubes. The seat is positioned so that the bottom of the pois on section is 2 in. below the core midplane. The seat also acts as the lower limit of travel for an operating control rod.

Although the full stroke of the operating control rods is 30 in., it is normally set at 20 in. during operation since the reactivity effect of the last 10 in. of withdrawal is small. Both rod drives are supplied with digital-readout, fine-position indication systems capable of showing the elevation of the drive extension to within \pm 0.03 in. The rod position is read on Gilmore indicators located in the reactor control room. 


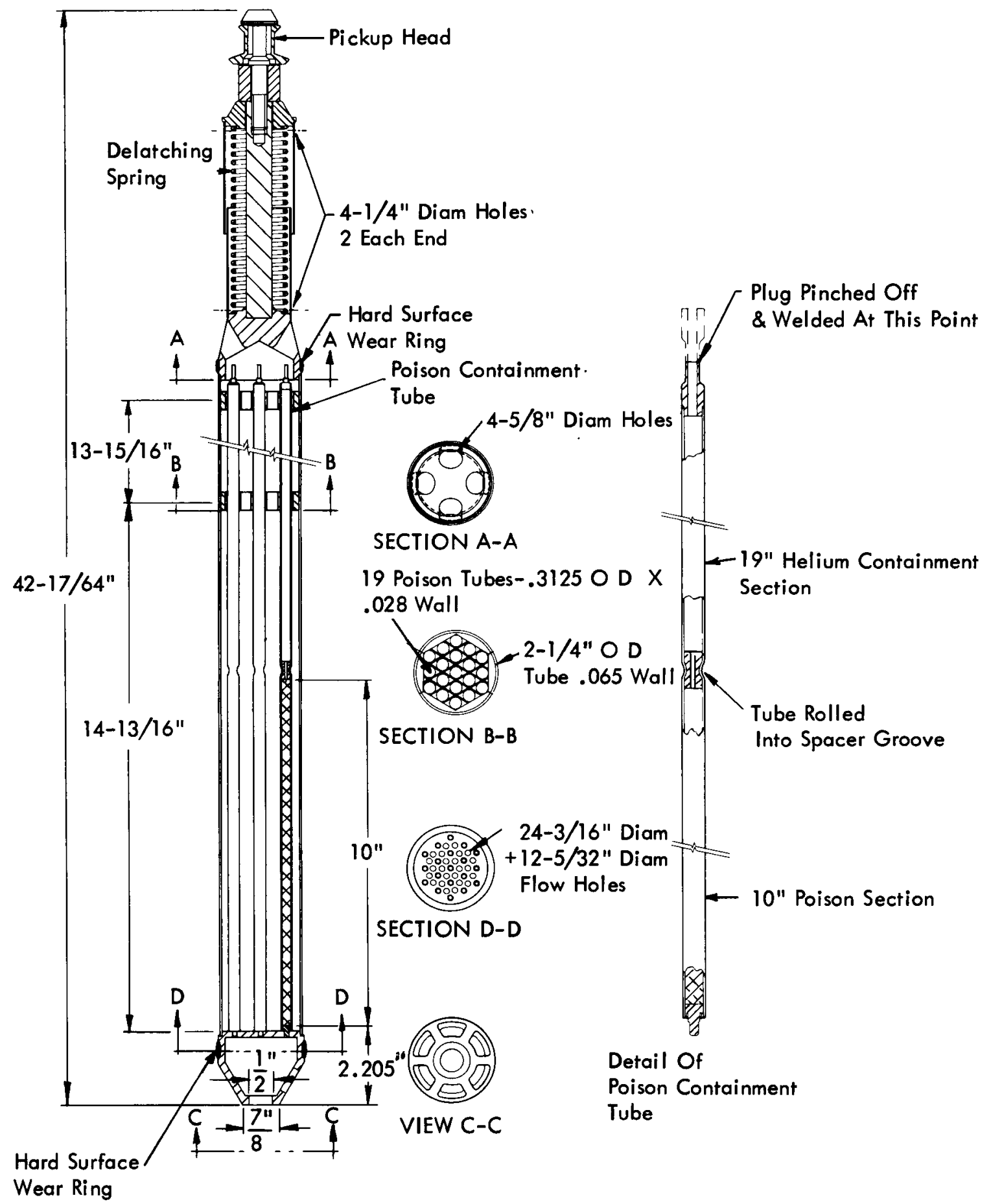

FIG.4 OPERATING CONTROL ROD 


\section{Safety Rods}

The eight safety rods are located at an average distance of 7 in. from the vertical centerline of the core and are spaced uniformly around the centerline (Fig. 2). Each rod is designated by a number, 1 through 8 , as shown in Fig. 6. Although the distances of all rods from the core center are not the same, there are only three different positions used for the eight rods. These are referred to as the typical safety rod positions. Since all safety rods are of identical design, the rods which occupy these positions are called typical rods, each of which has a different worth. Typical rods, and their companion rods (given in parentheses), a re rods $\operatorname{No} 1(3,6,8)$, No. 2 (7), and No. 4 (5).

The design of the safety rod guide tubes is essentially the same as that of the control rod guide tubes. The safety rods are also cooled in a manner similar to that of the control rods except that a reduced coolant flow rate is used because their normal operating position is above the core and less nuclear heat is generated in them.

The safety rod design is shown in Fig. 5. The four sections of the safety rod assembly are the dash ram, the poison section, the extension rod, and the pickup head. The poison section of each rod contains approximately $535 \mathrm{~g}$ of boron-10 in the form of 57 per cent enriched boron in $\mathrm{B}_{4} \mathrm{C}$, giving a negative reactivity worth of more than a dollar per rod. The poison section is approximately 36-in. long and the poison material is contained inside six hermetically-sealed stainless steel tubes. The poison containment tubes are designed as pressure vessels to contain the helium gas released as a result of the $(n, a)$ reaction in the boron-10. The dash ram is used to decelerate the safety rods after a scram. The extension rod connects the poison section to the pickup head. It contains a spring which helps accelerate the safety rod into the core. The pickup head connects to the safety rod drive extension by means of gripper fingers and a magnetic latching mechanism.

In the case of normal reactor startup, the ganged safety rods are driven out of the core slowly. Although the full stroke of the safety rods is 54 in., there are two subcritical stop points located near the end of the travel at which withdrawal is automatically stopped. By knowing the reactivity worth of the rods between stops, count rate data taken at the stops may be used to predict the degree of reactor subcriticality before the rods are fully withdrawn. This prevents criticality from being inadvertently achieved on the safety rods.

The rods are dropped into the reactor under the force of gravity when a scram signal causes the magnetic latch mechanism to de-energize and the fingers to release the rods. 


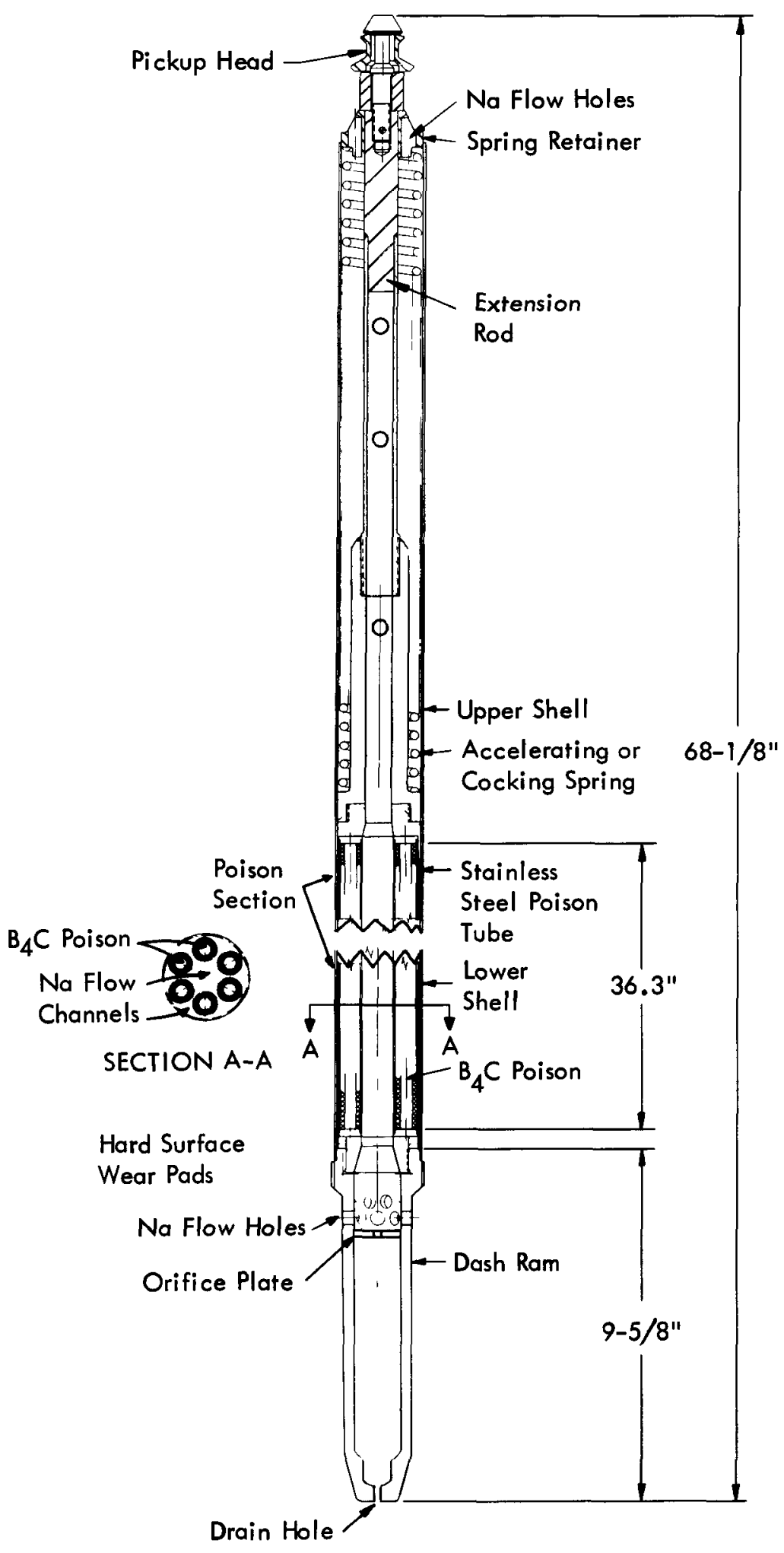

FIG.5 SAFETY ROD ASSEMBLY 
The rods can also be driven into or out of the core individually, if desired. The elevation of each of the safety rod drive extensions may be read on a Gilmore indicator located in the reactor control room. 


\section{EXPERIMENTAL PROCEDURE}

\section{A. DESCRIPTION OF THE TEST}

The calibration measurements of the control and safety rods for the Enrico Fermi reactor were made in accordance with detailed, preplanned procedures. 5, 6 Before the test, the procedures were reviewed for completeness and safety; revisions were made, where necessary, to facilitate the acquisition of complete and precise data during the test. The procedures were also used by the reactor operating staff for the preparation of operating guides for the conduct of the test.

Preliminary rod calibrations, adequate for operating the reactor, had been obtained by straightforward techniques early in the test program. 1,2,3 The purpose of this test was to obtain more accurate calibrations that included shadowing effects, for use in later experiments. Because of differences in the nuclear and mechanical designs of the various rods, and limitations on the operation of the reactor, rather complex procedures had to be used to calibrate all rods to the desired accuracy. The variety of methods used included positive and negative period measurements, subcritical count rate measurements, and intercalibration measurements between rods.

\section{Control Rod Calibration}

The control rod calibrations were made first so that they could be used later in intercalibration measurements with the safety rods. Data were obtained for both rods for the fully-shadowed (other rod fully inserted) and fully-unshadowed (other rod fully withdrawn) conditions, as well as for intermediate conditions of shadowing in the case of the regulating rod. Intermediate shadowing data for the shim rod were not necessary since reactivity measurements in experiments are normally made with the regulating rod, the shim rod remaining in a fixed position.

\section{a. Regulating Rod Calibration}

The regulating rod calibration consisted chiefly of positive period reactivity measurements. Positive period calibration was thought to be the most accurate of the several techniques available, and the regulating rod was well suited for this type of measurement since it is the faster moving rod.

Basically, the measurements were made as follows. The reactor was first made critical at low power on the regulating rod, with the source retracted and with the shim rod at the desired shadowing position. 
Following this, the regulating rod was successively stepped-out in increasing increments above its critical position, with the shim rod remaining fixed.

Each rod movement put the reactor on a positive period, which was measured on the neutron detection channels after each step. From these, the excess reactivity addition due to regulating rod motion could be determined relative to the initial critical position. The reactor power was reduced, and the regulating rod was returned to its initial critical position each time before making the next period measurement. When a series of such measurements had been completed at one shim rod shadowing position, the shim rod was moved to a new position and the procedure was repeated.

In practice, the measurements were restricted because positive periods less than 60 sec (13 cents excess reactivity) were not allowed. This limitation was set for safety reasons and also because of the decreased accuracy attainable with very short period measurements. As a result, the regulating rod could be calibrated over only a limited portion of its travel, at each shim rod shadowing position, by the method outlined above.

An additional problem was that the degrees of shim rod shadowing which could be investigated were quite limited for a particular excess reactivity loading. If the excess reactivity was small, the shim rod had to be located in the upper portion of its travel and vice versa.

To overcome these two problems and allow period calibration of the regulating rod over its full length of travel for all desired conditions of shim rod shadowing, it was necessary to make adjustments of excess reactivity throughout the course of the test. Starting with a loading that had an excess reactivity of 10 cents, the excess reactivity was increased in increments of 10 to 14 cents by means of six separate stepwise additions of core fuel subassemblies and inner radial blanket subassemblies, until, at the end of the test, the excess reactivity in the reactor was 89 cents. After each loading change, period calibration measurements were made at successive 2 -in, intervals in regulating rod position, as well as at 2 -in. intervals in the degree of shim rod shadowing, to the extent allowed by the limitations previously discussed. Each loading permitted investigation of a different portion of the rod travel and different degrees of shadowing; the loading increments used ensured overlap of measurements. Therefore, the full rod calibration was eventually obtained. *

The regulating rod could not be calibrated with the above procedure over its entire length of travel soley by means of positive period measurements. The first few inches of regulating rod travel upward from

* It was assumed that the rod calibration was not affected by the loading changes made. 
the fully-inserted position could not be calibrated by the procedure outlined above. This was true for all cases of shim rod shadowing investigated, but in varying degrees. It was the result of only relatively large reactivity steps being available to provide the excess reactivity shimming, i. e., it would have been extremely difficult to load the reactor so precisely that criticality could have been achieved with the regulating rod exactly fully inserted for each shim rod shadowing position investigated. Even if this could have been done, it would not have been desirable because there would have been no fast-acting rod available to provide for power reduction after the period measurement was made. This would be of concern from a safety viewpoint.

The calibration of the first few inches of rod travel was therefore made by means of negative period reactivity measurements. These were made in the same manner as the positive period measurements except that the regulating rod was inserted in 2 -in. increments from its critical position. Although negative period measurements are inherently less accurate than positive period measurements, the portion of the rod calibration obtained by them was also checked by subcritical count rate reactivity measurements, giving good correlation.

The period measurement calibrations were conducted at a nominal reactor is othermal temperature of $518 \mathrm{~F}$ and were made with the retractable source fully withdrawn, to eliminate source effects. The periods were measured on neutron detection channels and the results were averaged for use in the analysis. The period data were corrected for any temperature drift which occurred in the time between the initial reference critical measurement and the subsequent set of period measurements.

\section{b. Shim Rod Calibration}

The shim rod calibration could not be made by means of positive and negative period measurements, as used for the regulating rod, because of the slow rate of travel of the shim rod. The shim rod was therefore calibrated for the desired fully-shadowed and fully-unshadowed conditions by means of subcritical count rate measurements.

To make the measurements, the initial fuel loading configur ation of the reactor (minimum excess reactivity) was used. This was necessary so that the unshadowed data could be obtained.

To obtain the unshadowed data, the reactor was first made critical at low power on the regulating rod with the source retracted and the shim rod withdrawn 20 in. The critical regulating rod position for these conditions was somewhat less than 20 in., but by only a small amount because of the small excess reactivity. The worth of the regulating rod between its critical position and 20 in. was then determined by withdrawing the rod to 
20 in. and making a positive period measurement. After returning the regulating rod to its initial critical position, the reactor was made subcritical by inserting the retractable antimony source rod, which has a negative worth of approximately 7.80 cents. This allowed the regulating rod to be withdrawn to $20 \mathrm{in}$, , with the reactor remaining subcritical. The degree of subcriticality at this point could be determined from the source worth and from the regulating rod period data obtained earlier for 20-in. withdrawal. Count rate data were then taken to obtain the absolute relationship between count rate and subcritical reactivity. Finally, the shim rod was calibrated by stepping the rod in 2 -in. increments until it was fully inserted, constantly keeping the regulating rod fixed at 20 in. , and taking counts at each step after the count rate had stabilized.

To obtain the shadowed shim rod data, the regulating rod was next fully inserted, the shim rod was withdrawn to $20 \mathrm{in.}$, and the previous subcritical calibration procedure was repeated at 2 -in. insertion intervals.

Although the formal shim rod calibration was obtained by the subcritical technique outlined above, it could be checked for both shadowing conditions over most of the rod travel by another method. This was done by noting the change in critical shim rod position for each of the six fuel loadings, the measurements being made each time with the regulating rod either fully withdrawn and/or fully inserted, depending on the reactivity state of the reactor. These data were then related to reactivity by determining the excess reactivity added in each fuel loading. This was done by making positive period measurements for each new loading with the control rods set at their critical positions of the previous loading.

The subcritical reactivity measurements were also made at a nominal reactor isothermal temperature of $518 \mathrm{~F}$ and with the retractable source inserted. Several sets of count rate data were taken on the neturon detection channels at each rod position. The data were averaged for use in the analysis and were corrected for temperature drift between measurements, where necessary.

\section{Safety Rod Calibration}

The original intent of the test was to obtain the fully-unshadowed reactivity worth of each of the seven installed safety rods as a function of position, the fully-shadowed worth of each of the three typical rods, and the ganged worth of the seven rods. However, to save time, individual rod calibrations were made for only the three typical safety rods. These were rod Nos. 1, 2 and 4, which are located at core lattice positions symmetrical to the other rods (Fig. 6). This abbreviation was possible since the unshadowed worths obtained here for these rods were found to be in close agreement with the earlier results from other tests. 2,3 The earlier 


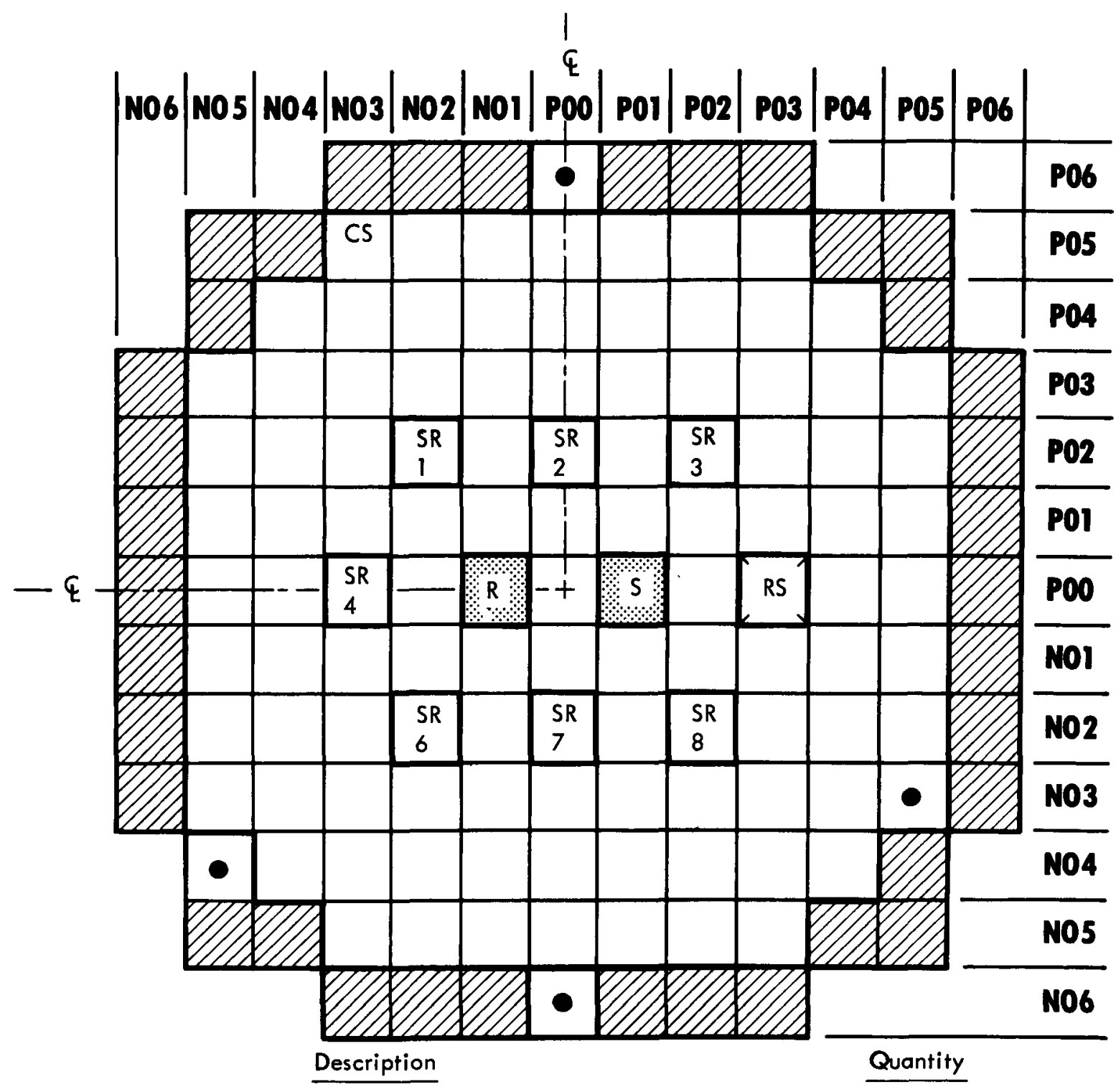

JOperating Control Rods .......... 2

SR Safety Rods . . . . . . . . . . 7

Core Subassemblies (25.6\% Enriched U-10 W/O

Mo Alloy; 4.74kg U-235/Subassembly) ... . 97

- Dummy Subassembly (No Fuel - Sodium Filled) . . 4

[RS]Retractable Source .......... I

Inner Radial Blanket Subassemblies-Depleted

ZU-3 W/O Mo Alloy ........ 37

Core Shim Subassembly (Approx One-half

CS Depleted, One-half Enriched Uranium -

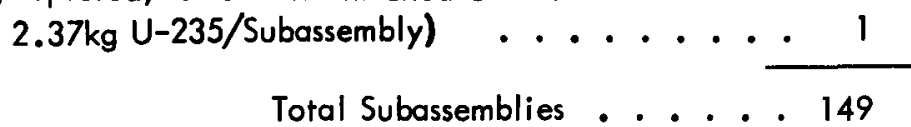

FIG.6 INITIAL CORE LOADING FOR ROD CALIBRATION MEASUREMENTS 
calibrations for the remaining rods were therefore substituted for the similar planned measurements in this test.

None of the safety rod calibrations could be made by means of period measurements because of the relatively slow rate of safety rod withdrawal. Intercalibration measurements using the previously calibrated control rods were used to some extent, but this method was limited by the maximum excess reactivity restrictions of the reactor. Consequently, subcritical count rate measurements were used for most of the calibrations.

All safety rod calibrations were performed at a nominal reactor is othermal temperature of $517 \mathrm{~F}$. They were made with the retractable source either inserted, for the subcritical measurements, or withdrawn, for the intercalibration measurements. The latter measurements were made with the reactor critical at low power. The excess reactivity of the reactor throughout the test was 89 cents, the last core loading configuration used for the control rod calibrations. The count rate data were obtained and analyzed in the way explained previously for the shim rod calibrations. The intercalibration data, being basically a series of critical control rod position measurements, required corrections for flux drift and temperature drift.

\section{a. Uns hadowed Worths}

The fully-unshadowed worths of the three typical safety rods were determined first. The calibrations were made using a combination of intercalibration and subcritical count rate measurements. A rod could not be fully calibrated using the intercalibration technique, since its anticipated negative worth was more than one dollar, and the reactor had only 89 cents positive excess reactivity, i. e., criticality on the control rods could not have been maintained with more than 89 cents of safety rod negative reactivity in the reactor.

To calibrate a rod, all (seven) safety rods were first fully withdrawn from the shutdown reactor, the control rods and retractable source being kept fully inserted. The reactor was slightly subcritical in this condition, and the amount of subcriticality was found next by determining the critical position of the previously calibrated regulating rod. The regulating rod was then reinserted and the correlation between subcritical count rate and reactivity was obtained.

Following this, the safety rod being investigated was fully inserted into the reactor and the two operating control rods were fully withdrawn. Count rate data were again taken. At this point, the reactor was subcritical by an amount equal to the reactivity difference between the sum of the negative worths of the safety rod and antimony source, approximately 
1. 30 dollars and 7.8 cents, respectively, and the available positive excess reactivity, 89 cents.

The rod under test was next withdrawn in 4 -in. increments, subcritical count rate data being taken on the neutron detection channels at each stop. This was continued until the position was reached where an additional 4-in. withdrawal at this point would have caused the reactor to go critical. Because of this, rod withdrawal to the next 4-in. increment was made as follows. The rod was withdrawn until the position was reached where the reactor became critical. This position was noted. Withdrawal was then continued with the subsequent reactivity addition resulting from safety rod withdrawal being balanced by insertion of the regulating rod. After the rod had reached the next 4-in. stop point, the source was retracted and its reactivity addition balanced by additional regulating rod insertion.

The safety rod worth over the transitional criticality 4 -in. increment was found knowing the source worth, the regulating rod calibration, and from calculations of subcritical reactivity which gave the degree of reactor subcriticality prior to beginning the step.

The remainder of the safety rod calibration was conducted at critical in a straightforward manner by means of intercalibration measurements, using the previously calibrated control rods. As the safety rod was stepped-out in 4-in. increments, its positive reactivity addition was balanced by negative reactivity addition resulting from simultaneous insertion of the control rods so that criticality was maintained. Due to the slow rate of shim rod travel, however, the axial positions of the regulating and shim rods had to be interchanged when the regulating rod became fully inserted.

\section{b. Shadowed Worths}

The fully-shadowed worths of each of the three typical safety rods were determined in a manner similar to that described for the unshadowed worths. The main exception was that the two safety rods adjacent to the rod being tested were initially inserted along with it, and remained inserted in the core during the measurements. It was assumed that shadowing effects were negligible for rods not adjacent to each other. The shadowed rod was then withdrawn in 4 -in. increments with subcritical count rate measurements being taken at each stop. In this case, all of the measurements were made subcritical since there was not enough excess reactivity available to attain criticality at any time during withdrawal of the shadowed rod.

\section{c. Ganged Worth}

The measurement of the worth of the ganged safety rods was made in the same manner as the unshadowed rod worth measurements al- 
ready described, i. e., by a combination of subcritical and intercalibration techniques. The difference in this case was that all (seven) rods were initially inserted into the core and then withdrawn simultaneously in 4 -in. increments, and special data were taken at the two subcritical stop points.

It was not expected that the ganged rod calibration by this method would be accurate. This was because the reactor was substantially subcritical over most of the rod travel, due to the large negative worth (estimated at more than 8.00 dollars) of the ganged safety rods, whereas the analysis was made by means of simple subcritical multiplication theory (See Section IV-B). This theory assumes a fundamental mode flux distribution, which is not true at large degrees of subcriticality.

However, the method was expected to give an accurate calibration of the two subcritical stops used for criticality prediction. These are located near the upper end of the rod travel, at approximately -50 cents and -25 cents; for this portion of the calibration, the control rods could be used for intercalibration measurements with the reactor critical.

The total ganged worth measured in this test was not considered important, since it was believed that a good ganged calibration had already been obtained in an earlier test. ${ }^{3}$ Also, it was known that it would be possible to calculate the ganged worth from the worths of the unshadowed and shadowed rods.

\section{B. REACTOR PLANT CONDITIONS}

The initial reactor fuel loading configuration used at the beginning of the test is shown in Fig. 6.* By means of the fuel substitutions in the core and inner radial blanket, shown in Table 1 , the excess reactivity was increased in six additional loadings from its initial value of 10 cents to approximately 89 cents. Table 1 gives the measured excess reactivity of each loading. The excess reactivity is defined as the reactivity at $517 \mathrm{~F}$ is othermal with all safety rods, control rods, and the retractable source fully withdrawn. Loadings 1 through 7 were needed for the control rod calibrations and loading 7 was used for the safety rod calibrations.

When possible, the primary system was maintained at the normal startup temperature of $517 \mathrm{~F}$ isothermal during the test, and the temperature drift between measurements was kept to a minimum. The reactor

* The coordinate system used to locate subassemblies in the core lattice is shown in Fig. 6. The first position number given is the $\mathrm{X}$-coordinate and the second is the $\mathrm{Y}$-coordinate. Positive and negative values are designated " $P$ " and " $N$ ", respectively; the core center is P00-P00. 
TABLE 1 - SUBASSEMBLY ADDITIONS AND EXCESS REACTIVITIES OF LOADINGS

\begin{tabular}{|c|c|c|c|c|c|}
\hline Loading & Date & $\begin{array}{l}\text { Substitutions Made } \\
\text { (S. A. = Subass embly) }\end{array}$ & $\begin{array}{l}\text { No. of Final } \\
\text { Core Configuration } \\
\text { Subassemblies } \\
\text { (Core, Shim, } \\
\text { (Dummy, IRB) } \\
\end{array}$ & $\begin{array}{l}\quad \text { Measured } \\
\text { Increase in Excess } \\
\text { Reactivity, cents } \\
\end{array}$ & $\begin{array}{c}\text { Final } \\
\text { Excess } \\
\text { Reactivity, } \\
\text { cents } \\
\end{array}$ \\
\hline 1 (Initial) & $10-23-63$ & --- & $97,1,4,37$ & - & 10.04 \\
\hline 2 & $10-25-63$ & $\begin{array}{l}\text { Core for Shim S. A. in N03-P05; } \\
\text { Dummy for IRB S.A. in } \\
\text { P06-P00 and N06-P00 }\end{array}$ & $98,0,6,35$ & 10.65 & 20.69 \\
\hline 3 & $10-26-63$ & Shim for IRB S. A. in P06-P0I & $98,1,6,34$ & 12.95 & 33.64 \\
\hline 4 & $10-28-63$ & Shim for IRB S. A. in N06-P0l & $98,2,6,33$ & 13.82 & 47.46 \\
\hline 5 & $10-29-63$ & $\begin{array}{l}\text { IRB for Shim S. A. in N06-P01 } \\
\text { and P06-P01; IRB for Dummy } \\
\text { S. A. in P06-P00 and N06-P00; } \\
\text { Core for Dummy S. A. in } \\
\text { P05-N03 }\end{array}$ & $99,0,3,37$ & 13.40 & 60.86 \\
\hline 6 & $10-30-63$ & Shim for IRB S. A. in P06-P0l & $99,1,3,36$ & 13.43 & 74.29 \\
\hline 7 & $10-31-63$ & Shim for IRB S. A. in N06-P01 & $99,2,3,35$ & 14.25 & 88.54 \\
\hline
\end{tabular}


temperature was controlled by maintaining a balance between the heat input which resulted from primary sodium pump operation, and the heat removal which resulted from operation of the below-floor ventilation system. The primary sodium flow rate required to maintain a temperature equilibrium of $517 \mathrm{~F}$ was approximately the refueling flow value of $6.0 \times 10^{6} \mathrm{lb} / \mathrm{hr}$ $\left(2.0 \times 10^{6} \mathrm{lb} / \mathrm{hr} /\right.$ loop). With this flow, and suitable adjustment of the secondary sodium and feedwater system conditions, the temperature drift rate was kept to within $\pm 0.25 \mathrm{~F} / \mathrm{hr}$. The auxiliary system, consisting of the overflow pump and primary system cold trap, was also operated, when required to reduce an upward drift in temperature.

The reactor was operated at a critical, steady-state power level of a few hundred watts during the test. The power was purposely kept low to minimize the activation of reactor components. When positive period measurements were made, the transient power was allowed to rise approximately one-half a decade above the critical power before the regulating rod was reinserted and the power reduced. The only limitation on power decrease during the negative period measurements was that the power was not allowed to decay so far that meaningful flux information to the safety system was lost. Because of the retractable source, source reactivity effects were negligible at all power levels during the critical rod and period measurements. Therefore, it was not necessary to accurately reproduce the power for each measurement. The subcritical measurements, made with the source inserted, were made at source power levels of only a few watts.

The trip setting of the reactor safety system for low sodium flow rate was reduced during the test from its normal setting of 75 per cent of the 200-Mwt design flow to 40 per cent of the 200-Mwt design flow. This was done because the refueling flow rate required for temperature equilibrium, $6.0 \times 10^{6} \mathrm{lb} / \mathrm{hr}$ or 68 per cent of the 200-Mwt flow rate, was less than the normal trip-point setting. Another safety system modification made for the test was that the scram levels for the intermediate and power range safety systems were set at flux levels corresponding to powers of approximately $1 \mathrm{Mwt}$. This prevented the reactor from inadvertently exceeding the maximum power level allowed for the low-power tests.

\section{NEUTRON SOURCE AND INSTRUMENTA TION}

During the test, a retractable neutron source was positioned in the reactor in the location normally occupied by safety rod No. 5. A temporary, precision-temperature readout station was set up in the reactor control room so that an accurate record of reactor temperature could be maintained. The subcritical count rate, positive and negative period, and power drift rate information required during the test were obtained from specially installed neutron detectors. The remaining test data, i.e., the primary sodium 
flow rates and the control rod and safety rod positions, were obtained from the permanent plant instrumentation.

\section{Neutron Source}

Throughout the rod calibration test, the retractable antimonyberyllium ( $\mathrm{Sb}-\mathrm{Be}$ ) neutron source replaced safety rod No. 5 in the core position P03-P00. The portion of the source $\left(T_{1 / 2}=60\right.$ days $)$ consisting of radioactive antimony -124 is a rod approximately 0.7 in. in diam by 25 -in. long. Its activity at the time of the test was about 120 curies. The antimony rod fits inside a hollow beryllium cylinder which is approximately $30-$ in. long and which contains $3.4 \mathrm{~kg}$ of beryllium. The beryllium cylinder is in turn located inside a square, steel can which has the external dimensions of a normal lower safety rod guide tube. To retract the source from the core, the handling head of the antimony section is engaged with the gripper of the safety rod drive extension.

The presence of the retractable source during the test permitted accurate reactivity measurements at low power, thus minimizing the activation of core components. The approach to criticality was made with the antimony source rod fully inserted. After criticality was attained at low power, the source was withdrawn from the core to eliminate source reactivity effects in the subsequent reactivity measurements. It was realized, however, that the beryllium can portion of the source would have a moderating effect on the core neutrons and as a result it would tend to enhance the worth of the nearby shim control rod calibrated in the test.

Calibration measurements ${ }^{7}$ made at the time the retractable source was installed had shown that, with the source retracted $30 \mathrm{in}$., source reactivity effects were negligible. They also showed that the antimony rod portion of the source had a negative reactivity worth of 7.80 cents.

The source was kept fully inserted for the subcritical reactivity measurements.

\section{Instrumentation}

The instrumentation used to monitor neutron flux during the test was essentially the same as that described in detail in Reference 1 . The only difference was that in this test no in-core instrumentation was used. This was because the temporary instrument thimble, normally installed during the low-power tests in place of safety rod No. 5, had been replaced by the retractable source.

All of the nuclear instrumentation used was temporary instrumentation, installed specially for the low-power test program. Briefly, it consisted of two high-sensitivity $\mathrm{BF}_{3}$ proportional detector channels and 
six B-10-lined ion chamber channels. All detectors were located inside the six neutron-counter tubes embedded in the graphite shield surrounding the reactor vessel (Fig. 1). The two $\mathrm{BF}_{3}$ detectors were connected to mechanical scalers located in the reactor control room. They provided data from which the subcritical count rates and reactor periods were determined in the test; they were also used to supply both count rate and period signals to the source range safety system of the reactor. Five of the six B-10-lined ion chambers provided power level protection for the intermediate and power range safety systems. The intermediate range detectors also provided period protection. The sixth ion chamber provided a linear current signal to a Keithley micro-microammeter recorder located in the reactor control room. This recorder also gave period information during the test and it was used to measure any drift in power which took place during the critical rod position reactivity measurements.

The temperature of the primary system was monitored during the test by use of the normal plant temperature-sensing elements. These sensing elements consist of iron-constantan thermocouples and platinum resistance temperature detectors. The thermocouples are installed on the fuel support plates located below the core and on the holddown plate located above the core; they measure the temperature of the core inlet and core outlet sodium, respectively. The resistance temperature detectors are located in the primary sodium piping leading to and from the reactor; they measure the temperature of the reactor inlet and outlet sodium. In the test, the data from all of these temperature sensors were relayed via special circuits to a temporary, precision-temperature readout station located in the reactor control room. The thermocouples were connected to a highsensitivity potentiometer, and the resistance detectors were connected to a resistance bridge. With the equipment used, temperatures could be read to an accuracy of $\pm 1 F$ and the reactivity data could be correspondingly corrected for temperature drift between measurements.

The permanent plant instrumentation ${ }^{4}$ was used to obtain the remaining required data. This consisted of primary sodium flow rates and control and safety rod positions. The primary sodium flowmeters, located in the control room, could be read to within $\pm 0.05 \times 10^{6} \mathrm{lb} / \mathrm{hr} /$ loop. The positions of the control and safety rods, read on the Gilmore indicators located in the control room, could be determined to within \pm 0.03 in. 
IV. METHOD OF ANALYSIS

The basic techniques used in this test to obtain the reactivity effect of a change in rod position were: (1) positive and negative period measurements; (2) subcritical count rate measurements; and (3) intercalibration measurements (critical rod position measurements). Application of these techniques is straightforward 8 and has been discussed in detail in other reports $2,9,10$; therefore, the methods of analysis will be reviewed only briefly.

\section{A. PERIOD CALIBRATION MEASUREMENTS}

The regulating rod was calibrated entirely by means of positive and negative period measurements. The rod positions were obtained from the Gilmore indicators. The period data were obtained from the two $\mathrm{BF}_{3}$ detector channels connected to scalers, and from the ion chamber channel connected to the Keithley micro-microammeter (Section III-C-2). Integrated counts taken from the scalers at 15 -sec intervals were plotted on semilogarithmic graph paper to obtain the periods. The Keithley signal operated a timer set to start and stop automatically on e-fold power increases, thus giving a direct readout of the reactor period. The three periods obtained were averaged for use in the analysis. The average period was converted to reactivity using the inhour relationship for the reactor. This was available in tabular form for increased accuracy.

As seen earlier, each period measurement gave the reactivity effect of rod motion relative to a reference critical rod position. Therefore, the data had to be corrected for any reactivity feedback resulting from temperature drift in the reactor in the time interval between the critical and period measurements. To do this, the is othermal temperature at the time of each measurement was determined, using the temperature sensors described earlier (Section III-C-2). Any temperature difference found was then multiplied by the value of the reactor is othermal temperature coefficient (determined in an earlier experiment ${ }^{10}$ ), to obtain the correction. This was the only correction to the period data required. No source reactivity correction was necessary because of the retractable source.

The complete series of regulating rod period calibration measurements was analyzed as outlined above. Thus, for each shim rod shadowing position, the rod worth over a limited portion of its travel was obtained relative to a series of reference critical positions of increasing rod insertion corresponding to the different loadings. Since care had been taken to make a period measurement each time using the critical rod position of the 
previous loading, the complete rod calibration normalized to zero worth fully inserted could then be obtained in a straightforward manner.

The accuracy of this method of calibration depended on the accuracy of the rod position, temperature, and period measurements. The uncertainty in each of these components had been estimated and a net calibration error had been calculated in earlier studies ${ }^{5}$. The results gave an estimated accuracy for the regulating rod calibration of approximately \pm 4 per cent for the total rod worth and \pm 2 per cent for the slope of the rod calibration curve.

\section{B. SUBCRITICAL COUNT RATE CALIBRA TION MEASUREMENTS}

The shim rod calibration data, and most of the measured safety rod calibration data, were obtained by means of subcritical count rate reactivity measurements. Rod positions were read from the Gilmore indicators. The count rate data were obtained from the two $\mathrm{BF}_{3}$ channels connected to scalers, and the data were averaged for use in the analysis. Care was taken to ensure that the count rate had stabilized before a measurement was made. The basic relationship between count rate and subcritical reactivity, as a function of rod position, is given by the following equation:*

$$
1-k_{2}=C_{1} / C_{2}\left(1-k_{1}\right)
$$

where,

$$
\begin{aligned}
C_{1}= & \text { the initial count rate obtained with the rod under test } \\
& \text { either fully withdrawn or fully inserted, cpm }
\end{aligned}
$$

* Derived from simple subcritical multiplication theory:

If,

Then,

$$
M a\left(1-k_{e f f}\right)^{-1}
$$

Thus,

$$
C=A\left(1-k_{e f f}\right)^{-1}
$$

$$
C_{1} / C_{2}=\frac{1-k_{2}}{1-k_{1}}
$$

where,

$$
\begin{aligned}
M= & \text { the source multiplication } \\
\left(1-\mathrm{k}_{\mathrm{eff}}\right)= & \text { the subcritical reactivity } \\
\mathrm{C}= & \text { the count rate } \\
\mathrm{A}= & \text { a constant which depends on the source strength, } \\
& \text { the energy of the source neutrons, the geometry } \\
& \text { of the source and detectors, and the type of detector }
\end{aligned}
$$




$$
\begin{aligned}
\mathrm{C}_{2}= & \begin{array}{l}
\text { the count rate obtained at intermediate positions of } \\
\text { insertion or withdrawal, } \mathrm{cpm}
\end{array} \\
1-\mathrm{k}_{1}= & \text { the amount the reactor was subcritical, initially, cents } \\
1-\mathrm{k}_{2}= & \begin{array}{l}
\text { the amount of subcriticality at the intermediate rod } \\
\text { positions, cents }
\end{array}
\end{aligned}
$$

The initial subcriticality, $1-k_{1}$, for the unshadowed shim rod calibration was that which existed with the shim and regulating rods fully withdrawn prior to the measurements. It was determined from the retractable source worth and from the period measurement made with the regulating rod at 20 in., as described earlier (Section III-A-1).

For the shadowed shim rod measurements, $1-k_{1}$ was the reactivity with the regulating rod fully inserted and the shim rod fully withdrawn. The value of $1-k_{1}$ in this case was found by using an equation identical to Eq. (1), but with the terms defined somewhat differently. In particular, $1-k_{2}$ was defined as the subcritical reactivity with both control rods fully withdrawn, i. e., it had the same value as $1-k_{1}$ in the unshadowed shim rod calibration. The count rate data obtained with both rods fully withdrawn versus that obtained with the regulating rod fully inserted could then be used to calculate the desired value of $1-k_{1}$ needed for the shadowed shim rod calibration.

In the case of the subcritical safety rod calibrations, $1-k_{1}$ was the subcritical reactivity with the rod(s) under test fully inserted, prior to beginning the withdrawal measurements. Similar to the case of the shadowed shim rod calculation, $1-k_{1}$ was calculated using Eq. (1) with the terms defined differently. In particular, $1-k_{2}$ was defined as the subcritical reactivity with all safety rods fully withdrawn, and both control rods and the source fully inserted. This reactivity was determined from the critical regulating rod position found prior to safety rod insertion and control rod withdrawal (see Section III-A-2) and the value of $1-k_{1}$ could then be calculated using the appropriately measured count rates $C_{1}$ and $C_{2}$.

Corrections for temperature drift occurring between the initial count rate measurement and subsequent measurements in a series were made in the same manner as described earlier for the period measurements. No correction for source decay was required because the measurements were made over a time interval which was short, relative to the half-life of the source.

The rod worths found from the above analysis were in the form of subcritical reactivity as a function of rod position relative to an initial subcritical reactivity. The desired rod calibration, normalized to zero worth at the fully-inserted position, could then be obtained by subtracting the initial subcritical reactivity from each value. 
The accuracy of this calibration method depended on the accuracy of the rod position, temperature, initial subcriticality, and count rate measurements. Calibration accuracy also depended on the validity of Eq. (1). Neglecting this latter point for the moment, it can be seen that the subcritical count rate calibrations were inherently less accurate than the regulating rod period calibrations. This is because, in addition to the other uncertainties, the regulating rod calibration was used to obtain the initial subcriticality values. An error analysis made for the subcritical rod calibrations on this basis, 5,6 showed that they had an uncertainty about twice as large as the regulating rod period calibration uncertainty, i. e. , \pm 8 per cent in the rod worth and \pm 4 per cent in the slope of the curve.

The extent to which Eq. (1) was valid in the calibrations is conjectural. Its derivation assumes that all generations of the neutron flux in the core resulting from the multiplication of source neutrons have a fundamental mode distribution, both in energy and space. When the reactor is close to criticality, this assumption is true. However, when the reactor is farsubcritical, this is not true, and the subcritical reactivity does not vary linearly with the inverse of the detector responses as given by Eq. (1). Calculations for the Fermi reactor for the case where the source is located near the core center indicate that appreciable errors using Eq. (1) begin to appear at -2.50 to -3.00 dollars, subcritical. 11 In addition to this source of error, nonlinear perturbations in the detector response can also occur as a result of the geometrical relationship between the source and detectors, and the effects of flux and spectral perturbations due to core inhomogeneities. Therefore, the exact point at which Eq. (1) becomes invalid is conjectural.

In the case of the shim rod and individual safety rod calibrations made at moderate degrees of subcriticality $(<4$ dollars), it was assumed that use of Eq. (1) caused no significant errors. In the case of the ganged safety rod calibration measurements, a portion of which was made with the reactor far-subcritical, significant errors over part of the calibration due to nonlinearities in the detector response were anticipated. As will be seen later, some error occurred.

\section{INTERCA LIBRATION MEASUREMENTS}

The major portion of the unshadowed individual safety rod calibrations and a small portion of the ganged safety rod calibration were obtained by means of intercalibration measurements made at criticality, using the previously calibrated control rods. Only the last part of the rod withdrawal was calibrated in this way, however, the initial withdrawal being calibrated subcritically.

The intercalibration data were obtained in a straightforward manner by measuring the amount of control rod insertion needed to compensate for 
the reactivity addition resulting from safety rod withdrawal. The rod position data were converted to reactivity using the control rod calibration curves, assuming that neither the control rod or safety rod calibrations were affected by the presence of the other rod. Temperature drift corrections were made to the data as before. The desired normalization of the intercalibration data for the upper rod travel was obtained by adding to each data point the total rod worth obtained from subcritical measure ments for the lower travel. The estimated uncertainty in the intercalibration measurements is \pm 6 per cent in the rod worth and \pm 3 per cent in the curve slope. 6 
-

. 


\section{EXPERIMENTAL RESULTS}

A large amount of data for period, count rate, rod position, and temperature were obtained in the rod calibration experiments. These data and the results of the various data-reduction steps (data averaging, reactivity conversion, temperature correction, worth normalization) are not included here since the details of the experiments have been previously explained. Therefore, only the final results of the test are given. These are compared with predictions, and a short discussion of the results is given.

The preliminary rod calibration results obtained in other tests $1,2,3$ are not given here, except in those cases where they are needed to fill in gaps in the experimental data, i. e., the safety rod calibrations. No large discrepancies were found between the preliminary calibrations and the comparable results of this test.

\section{A. CONTROL ROD CALIBRATIONS}

\section{Regulating Rod Calibration}

The results of the regulating rod calibration, shown in Table 2, give the regulating rod worth for 0 to 20 in. of withdrawal at 2 -in. increments in shim rod shadowing between 0 and 20 in. Also given is a calibration of the regulating rod worth for 0 to 30 in. of withdrawal with the shim rod set at 30 in. The latter calibration was not specified in the original procedure, since it is beyond the normal operating range of either rod; however, it was added to obtain an indication of the maximum excess reactivity which could be held down by one rod.

In Table 2 it appears that many of the regulating rod positions were chosen in a rather haphazard fashion, i.e., there are many noninteger positions at which calibration data were obtained, and they vary with the degrce of shadowing. The reason for this is that no control could be maintained over the critical regulating rod positions found prior to making period measurements, when the shim rod was set at 2 -in. integer shadowing intervals in each of the seven test loadings.

No attempt was made in Table 2 to show the different loadings in which the various data were obtained. However, a delineation between positive and negative period data was made. The positive period data are on the right of the heavy black line and the negative period data are on the left of the line. 
TABLE 2 - REGULATING ROD CALIBRATION

\begin{tabular}{|c|c|c|c|c|c|c|c|c|c|c|c|c|c|c|}
\hline \multirow{3}{*}{$\begin{array}{c}\text { Shim Rod Withdrawal, } \\
\text { in. } \\
0 \\
\text { (fully-shadowed) }\end{array}$} & \multicolumn{14}{|c|}{ Calibration Values * } \\
\hline & \multicolumn{14}{|c|}{$\begin{array}{l}\text { Regulating Rod Withdrawal, in. } \\
\text { Worth, inhours }\end{array}$} \\
\hline & $\frac{1.0}{6.68}$ & $\frac{2.0}{14.50}$ & $\frac{3.42}{26.50}$ & $\frac{4.0}{31.90}$ & $\frac{6.0}{52.11}$ & $\frac{7.57}{68.80}$ & $\frac{10.0}{92.15}$ & - & $\frac{12.0}{107.94}$ & $\frac{12.24}{109.83}$ & $\frac{14.0}{120.72}$ & $\frac{16.0}{129.51}$ & $\frac{18.0}{134.89}$ & $\frac{20.0}{139.52}$ \\
\hline 2 & $\frac{1.0}{6.31}$ & $\frac{1.79}{12.39}$ & $\frac{4.0}{31.85}$ & $\frac{6.0}{52.31}$ & $\frac{6.12}{54.13}$ & $\frac{8.0}{73.79}$ & $\frac{10.0}{92.78}$ & $\frac{10.32}{95.50}$ & $\frac{12.0}{108.51}$ & $\frac{14.0}{120.58}$ & - & $\frac{16.0}{129.79}$ & $\frac{18.0}{135.38}$ & $\frac{19.21}{138.06}$ \\
\hline 4 & $\frac{2.0}{16.28}$ & $\frac{4.16}{36.13}$ & - & $\frac{6.0}{55.59}$ & $\frac{8.0}{76.34}$ & $\frac{8.18}{77.87}$ & $\frac{10.0}{95.09}$ & - & $\frac{12.0}{110.52}$ & $\frac{13.52}{120.25}$ & - & $\frac{16.0}{131.59}$ & $\frac{18.0}{137.24}$ & $\frac{20.0}{141.68}$ \\
\hline 6 & $\frac{1.69}{11.55}$ & $\frac{4.0}{32.62}$ & - & $\frac{6.0}{53.58}$ & $\frac{6.03}{54.04}$ & $\frac{8.0}{74.88}$ & $\frac{10.0}{93.92}$ & $\frac{10.32}{96.34}$ & $\frac{12.0}{109.36}$ & $\frac{14.0}{121.77}$ & - & $\frac{16.0}{130.10}$ & $\frac{18.0}{135.55}$ & $\frac{19.52}{139.78}$ \\
\hline 8 & $\frac{2.0}{14.80}$ & $\frac{3.89}{32.07}$ & - & $\frac{6.0}{54.45}$ & $\frac{7.88}{74.24}$ & $\frac{8.0}{75.64}$ & $\frac{10.0}{94.82}$ & $\frac{12.0}{110.80}$ & $\frac{12.97}{117.68}$ & $\frac{14.0}{123.37}$ & - & $\frac{16.0}{132.14}$ & $\frac{18.0}{137.50}$ & $\frac{20.0}{141.85}$ \\
\hline 10 & $\frac{1.71}{12.30}$ & - & $\frac{4.0}{32.73}$ & $\frac{6.0}{54.37}$ & $\frac{8.0}{76.34}$ & $\frac{10.0}{95.71}$ & $\frac{10.17}{98.05}$ & $\frac{12.0}{112.44}$ & - & $\frac{14.0}{124.77}$ & $\frac{16.0}{133.40}$ & $\frac{18.0}{138.86}$ & $\frac{19.08}{141.34}$ & $\frac{20.0}{142.34}$ \\
\hline 12 & $\frac{2.0}{17.94}$ & - & $\frac{4.51}{42.15}$ & $\frac{6.0}{58.47}$ & $\frac{8.0}{80.81}$ & $\frac{8.4}{85 . \overline{3} 1}$ & $\frac{10.0}{100.82}$ & $\frac{12.0}{117.30}$ & $\frac{13.80}{127.86}$ & $\frac{14.0}{129.79}$ & - & $\frac{16.0}{137.40}$ & $\frac{18.0}{142.94}$ & $\frac{20.0}{146.91}$ \\
\hline 14 & $\frac{2.0}{14.84}$ & $\frac{3.22}{25.51}$ & $\frac{4.0}{33.26}$ & $\frac{6.0}{55.07}$ & $\frac{7.16}{68.78}$ & $\frac{8.0}{77.59}$ & $\frac{10.0}{97.62}$ & $\frac{11.77}{111.30}$ & $\frac{12.0}{113.90}$ & $\frac{14.0}{125.80}$ & - & $\frac{16.0}{134.33}$ & $\frac{18.0}{139.80}$ & $\frac{20.0}{143.86}$ \\
\hline 16 & $\frac{2.19}{15.77}$ & $\frac{4.0}{32.43}$ & $\frac{5.5}{48.80}$ & $\frac{6.0}{54.36}$ & $\frac{6.4}{59.17}$ & $\frac{8.0}{76.99}$ & - & $\frac{10.0}{96.74}$ & $\frac{10.64}{101.68}$ & $\frac{14.0}{124.87}$ & - & $\frac{16.0}{133.75}$ & $\frac{17.08}{136.59}$ & $\frac{18.0}{138.80}$ \\
\hline 18 & $\frac{1.47}{9.78}$ & $\frac{4.0}{32.40}$ & $\frac{5.5}{48.37}$ & $\frac{5.93}{53.88}$ & $\frac{6.0}{54.05}$ & $\frac{8.0}{76.29}$ & $\frac{9.54}{91.84}$ & $\frac{10.0}{95.82}$ & $\frac{12.0}{112.18}$ & $\frac{14.0}{124.76}$ & $\frac{15.29}{130.70}$ & $\frac{16.0}{133.30}$ & $\frac{18.0}{139.07}$ & $\frac{20.0}{143.14}$ \\
\hline $\begin{array}{c}20 \\
\text { (fully-unshadowed) }\end{array}$ & $\frac{0.87}{5.40}$ & $\frac{2.0}{14.27}$ & $\frac{4.0}{32.02}$ & $\frac{5.5}{49.51}$ & $\frac{6.0}{54.48}$ & $\frac{8.0}{76.21}$ & $\frac{9.54}{91.81}$ & - & $\frac{12.0}{111.50}$ & $\frac{14.0}{124.13}$ & $\frac{14.36}{126.11}$ & $\frac{16.0}{132 . \overline{95}}$ & $\frac{18.0}{13 \overline{3} 8.65}$ & $\frac{20.0}{142.98}$ \\
\hline $\begin{array}{c}30 \\
\text { (nonoperating position) }\end{array}$ & $\frac{9.0}{90.05}+$ & $\frac{13.22}{125.05}$ & $\frac{14.0}{129.79}$ & $\frac{16.0}{138.75}$ & $\frac{18.0}{144.48}$ & $\frac{20.0}{148.84}$ & $\frac{22.0}{152.12}$ & $\frac{24.0}{153.91}$ & $\frac{25.0}{154.52}$ & $\frac{26.0}{155.07}$ & $\frac{27.0}{155.36}$ & $\frac{28.0}{155.61}$ & $\frac{29.70}{155.79}$ & $\frac{30.0}{156.09}$ \\
\hline
\end{tabular}

* All calibrations normalized to zero worth for full rod insertion (zero-in. withdrawal)

$\dagger$ Extrapolated from the shim rod data at 20 in. Calibration data with the shim rod set at 30 in. were obtained only for withdrawal of 9 in. through 30 in., the 9 in. -13.22 in. calibration being based on negative period measurement and the remaining portion being based on positive period measurement. To obtain the complete calibration, it was observed that these data indicated a 3-1/2-per cent increase in the slope of the calibration curve compared with the 20 -in. shadowing case. Therefore, the rod worth between 0 in. and 9 in., with the shim rod at 20 in., was multiplied by 1.035 to obtain the value shown. 
Table 2 shows that the fully-shadowed worth of the regulating rod obtained was 139.52 inhours (43.74 cents), whereas the fully-unshadowed worth was 142.98 inhours ( 44.82 cents). The shadowed worth is therefore about $2-1 / 2$ per cent smaller than the unshadowed worth.

The fully-shadowed and fully-unshadowed data a re plotted in Fig. 7 , together with the predicted worth curves obtained in the critical experiment. 12 The predicted worths, 148.1 inhours (46.43 cents) and 153.0 inhours (47.96 cents), respectively, are both about $6-1 / 2$ per cent larger than those measured. The predicted reduction in rod worth due to shadowing is therefore about 3.2 per cent, compared to the measured value of 2-1/2 per cent. The shapes of the predicted and measured calibration curves are very similar, the measured curve being somewhat flatter.

The agreement between measurement and prediction shown in Fig. 7 is considered good. A direct comparison of the two sets of results cannot be made, however, because of the following differences in the two cases.

(a) Since the time of the critical experiment, the core design has been changed. The fuel enrichment was uniformly decreased by about 2 per cent, from $26.1 \mathrm{w} / \mathrm{o} U-235$ to 25.6 w/o U-235. This resulted in an approximate 8 per cent increase in core size. The worth of the rod, in terms of its effect on $\Delta \mathrm{k}$ (the effective multiplication factor), is decreased because of the increased core size. However, its worth in dollars $\left(\$=\frac{\Delta k}{\beta_{\text {eff }}}\right)$ increases because of a proportionally larger decrease in the $\beta$ eff value for the reactor.

(b) The control rod design has been changed since the time of the critical experiment. The enrichment of the boron in the $\mathrm{B}_{4} \mathrm{C}$ of the rod was increased from $18.8 \mathrm{w} / \mathrm{O} \mathrm{B}-10$ (natural B) to $34 \mathrm{w} / \circ \mathrm{B}-10$, keeping the total weight of B-10 in the rod constant $(88 \mathrm{~g})$. This results in a decrease in rod worth because of the increased self-shielding in the rod.

(c) The control rods were calibrated over only a 19-in. stroke in the critical experiment, whereas in the test the calibration was for 20-in. withdrawal (see Fig. 7). The critical experiment worth for 20 in. of withdrawal would be slightly larger than that given.

The net effect of items (a), (b), and (c) on the agreement between measured and predicted rod worth, although relatively small and somewhat compensating, has not been examined in detail and will not be considered further here. 


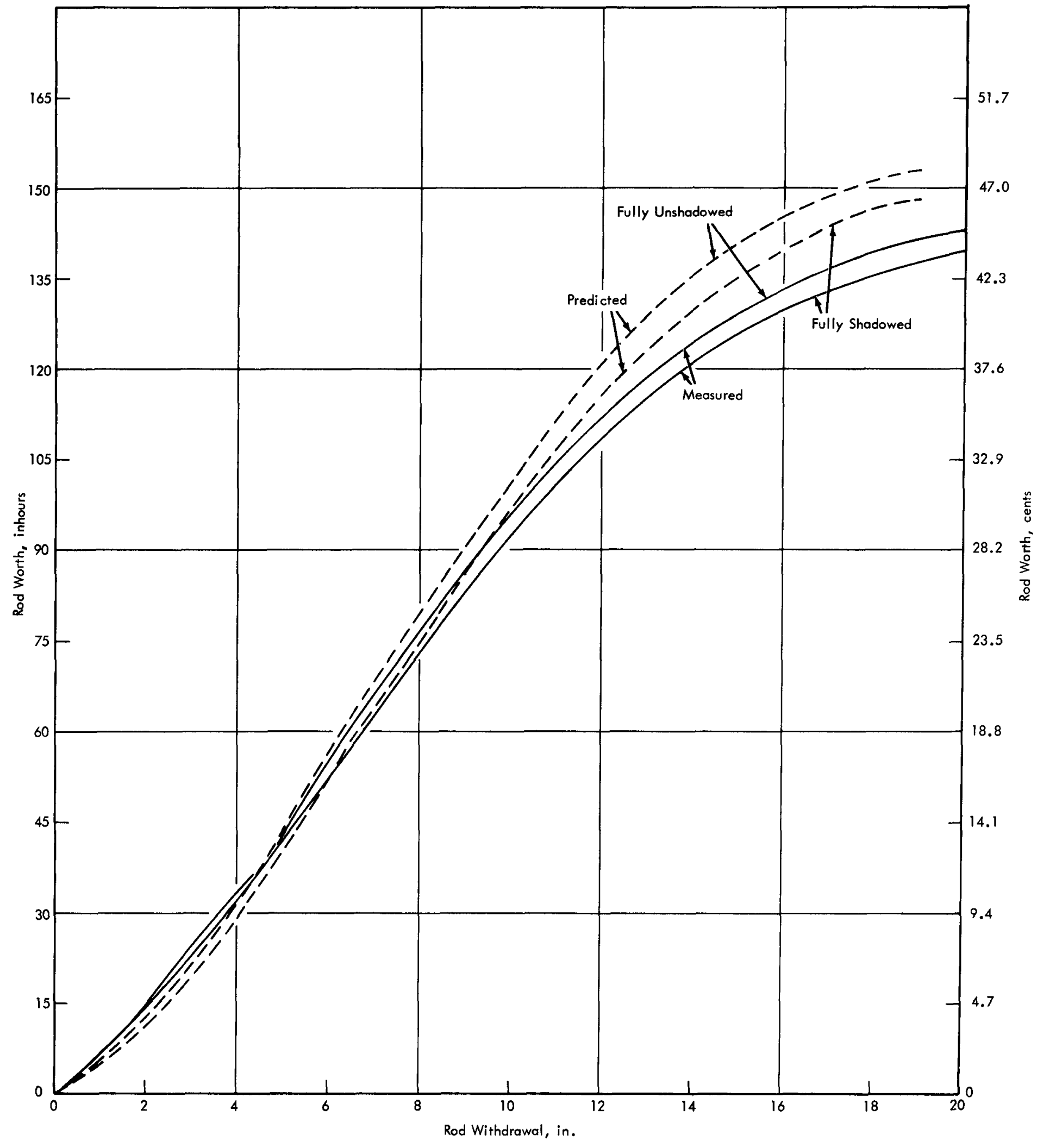

FIG.7 REGULATING ROD CALIBRATION CURVES 
Two additional points in Table 2 should also be mentioned. First, is the rather peculiar behavior in regulating rod worth measured at intermediate conditions of shadowing. The data show that although the minimum rod worth is obtained with the shim rod fully inserted, as expected, and the rod worth increases fairly uniformly upon initial shim rod withdrawal, also as expected, that when the shim rod withdrawal reaches 12 in. the regulating rod worth attains a maximum. Following this, the regulating rod worth decreases slightly with further shim rod withdrawal. Therefore, there appears to be less shim rod shadowing at 12 in. than at 20 in. No predictions of intermediate shadowing effects were made in the critical experiment to which these results can be compared.

The second point is the observed crossover in the calibration curves of the fully-unshadowed and fully-shadowed regulating rod at 4 in. of withdrawal (see Fig. 7). This effect is similar to that discussed above in that the shadowed rod appears to be worth slightly more than the unshadowed rod, but only for the first 4 in. of withdrawal. Similar behavior can also be seen in some of the other data in Table 2 .

The two effects discussed above are relatively small, and could possibly be attributed to "experimental uncertainties". However, it appears valid that the regulating rod attains its maximum worth at an intermediate condition of shadowing. There is a complex geometrical situation which exists in the reactor during rod withdrawal due to the fact that the poison sections of the control rods are only 10 -in. long, whereas the total travel of each rod is 20 in. The crossover effect is more difficult to explain. It could result from geometry, also. However, since the reactivity differences involved are quite small, and since they occur primarily for only small withdrawals where the calibration was made by less accurate negative period measurements, the crossover can probably be attributed to experimental uncertainties more than anything else.

One further clarification should be made. Although the measured shadowed worth of the regulating rod was $2-1 / 2$ per cent less than the unshadowed worth, this implies that the shadowing effect of one rod on another rod is actually only one-half of this, or 1-1/4 per cent. This is true because mutual shadowing or coupling between the two identical rods can be assumed. * This distinction is not important here, but it will be important later on when the safety rod results are considered.

* Another way of looking at this is that when the shadowed regulating rod is withdrawn from the core, a smaller net reactivity addition is seen, compared to the unshadowed case, because of the combination of (1) the reduced regulating rod worth due to the shim rod shadowing on it, and (2) the increased (negative) worth of the shim rod, as the regulating rod is withdrawn, due to the elimination of the regulating rod shadowing on it. These two shadowing effects are equal for identical rods. 


\title{
2. Shim Rod Calibration
}

The results of the shim rod calibration, shown in Table 3 , give the shim rod worth for 0 to 20 in. of withdrawal for the fully-shadowed and fully-unshadowed cases.

All data were obtained by subcritical count rate measurements. Because of this, the measurements could be made at any shim rod position desired and no haphazard array of noninteger positions appears, as in Table 2. Both calibrations were made at 2 -in. intervals in shim rod position.

\section{TABLE 3 - SHIM ROD CALIBRATION}

Shim Rod

Withdrawal, in.

\author{
Zero in. (fully-shadowed)
}

20 in. (fully-uns hadowed)

0
2
4
8
12
14
16
18
20

0

11.89

34.62

74.10

112.16

125.60

134.93

140.71

146. 74
0

15.32

34.05

80.67

118.97

132.48

141.47

147.39

151.66

Table 3 shows that the measured fully-shadowed worth of the shim rod was 146.74 inhours ( 46.0 cents), whereas the fully-unshadowed worth was 151.66 inhours (47.54 cents). The shadowed worth is therefore about 3.2 per cent less than the unshadowed worth.

The shim rod data are plotted in Fig. 8. The predicted curves are not shown since they are the same as those given earlier for the regulating rod, the two rods being identical and located at symmetrical lattice positions. The predicted shadowed and unshadowed worths are therefore 46.43 cents and 47.96 cents, respectively, with a 3.2 per cent predicted reduction due to shadowing.

The measured shim rod worths are in very close agreement with the predicted values. As shown below, the agreement is fortuitous. The worths are not consistent with the regulating rod results obtained earlier, 


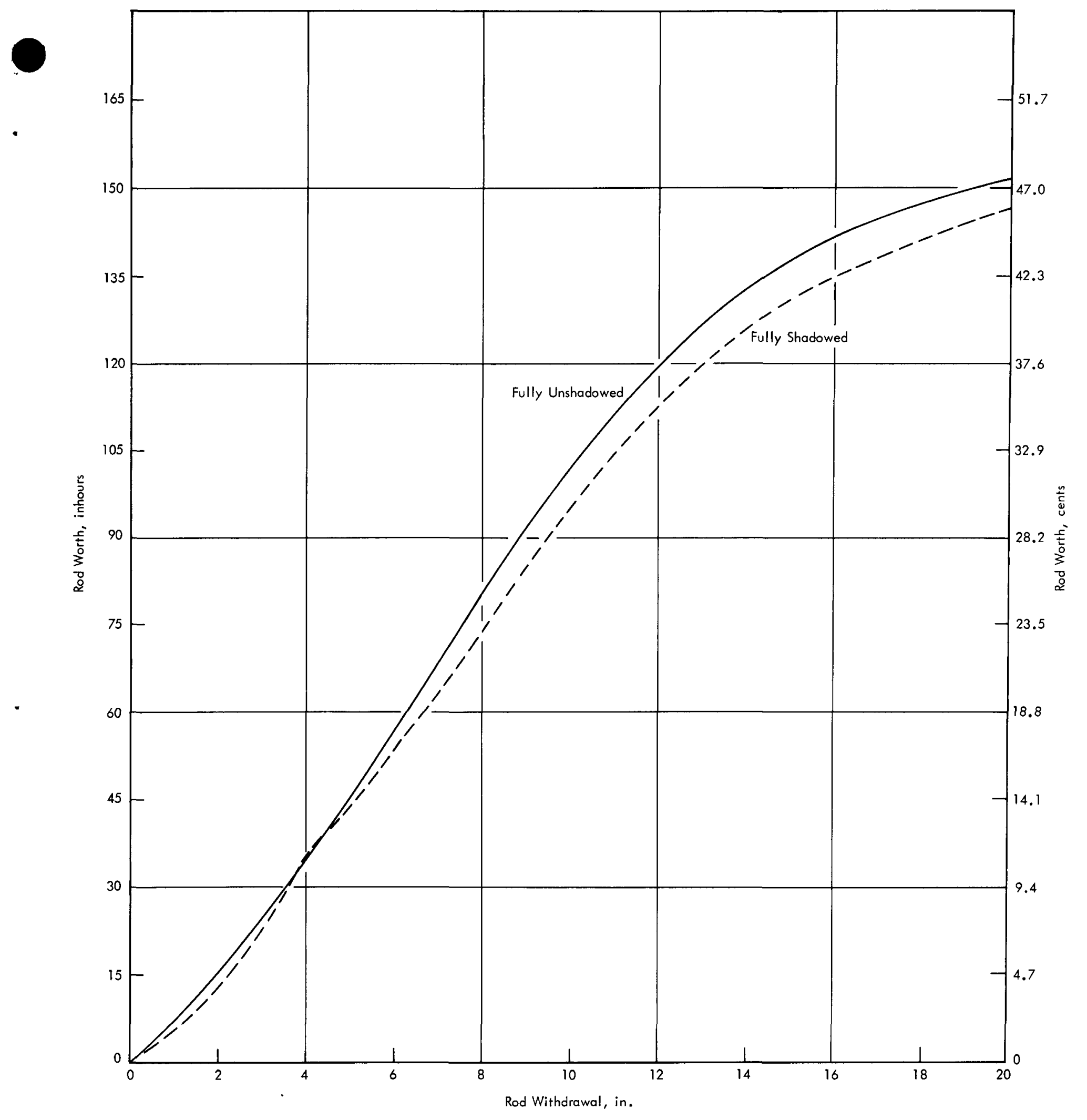

FIG.8 SHIM ROD CALIBRATION CURVES, MEASURED 
the comparable shim rod worths being about 5-1/2 per cent larger, on the average.*

The explanation for the close agreement of the shim rod worth with prediction, and its disagreement with the regulating rod worth has been attributed to the presence of the retractable neutron source during the test. As seen earlier, the source was located near the shim rod during the test, in lattice position P03-P00, and it contained $3.4 \mathrm{~kg}$ of beryllium in the form of a hollow cylinder of the same height as the core. The moderation of core neutrons in the vicinity of the shim rod by the beryllium is believed to have been a perturbational effect that would tend to enhance the rod worth. Evidence of this was seen at the time the source was installed. Preliminary measurements then indicated a shim rod worth increase of 5 to 10 per cent due to the source.13

It may be assumed that, in the absence of the retractable source, the shim rod worth would be very nearly the same as that measured for the regulating rod. Although intermediate shadowing measurements were not made, the shim rod probably has its maximum worth at an intermediate condition of shadowing also. There is some evidence in Table 3 and Fig. 8 of a crossover effect in the calibration curves of the fully-shadowed and fully-unshadowed shim rod at $4-i n$. withdrawal, but it is not as pronounced as in the case of the regulating rod.

\section{B. SAFETY ROD CALIBRATION}

1. Calibration of Individual Rods

The results of the fully-unshadowed and fully-shadowed calibrations of the three typical safety rods (Nos. 1, 2, and 4) are shown in Figs. 9,10 , and 11 , respectively. The unshadowed worths obtained in each case

\footnotetext{
* An indication of the accuracy achieved in the shim and regulating rod calibrations can be obtained by comparing the sum of the unshadowed shim rod worth and shadowed regulating rod worth to the sum of the shadowed shim rod worth and unshadowed regulating rod worth. These two sums should be equal since the net effect on reactor reactivity is the same whether the regulating rod is withdrawn before the shim rod or vice versa. From the rod calibration data, the two forementioned sums are 91.28 cents and 90.82 cents, respectively. The difference of 0.46 cents is therefore an indication of the total experimental error (rms) in the four calibrations. The statistical error in any one calibration, assuming no systematic errors and equal errors in each, is then approximately \pm onehalf $(1 / \sqrt{4})$ of 0.46 cents or \pm 0.23 cents. This is only $1 / 2$ per cent error and much better than had been predicted (Section IV-A).
} 
Cents Inhours

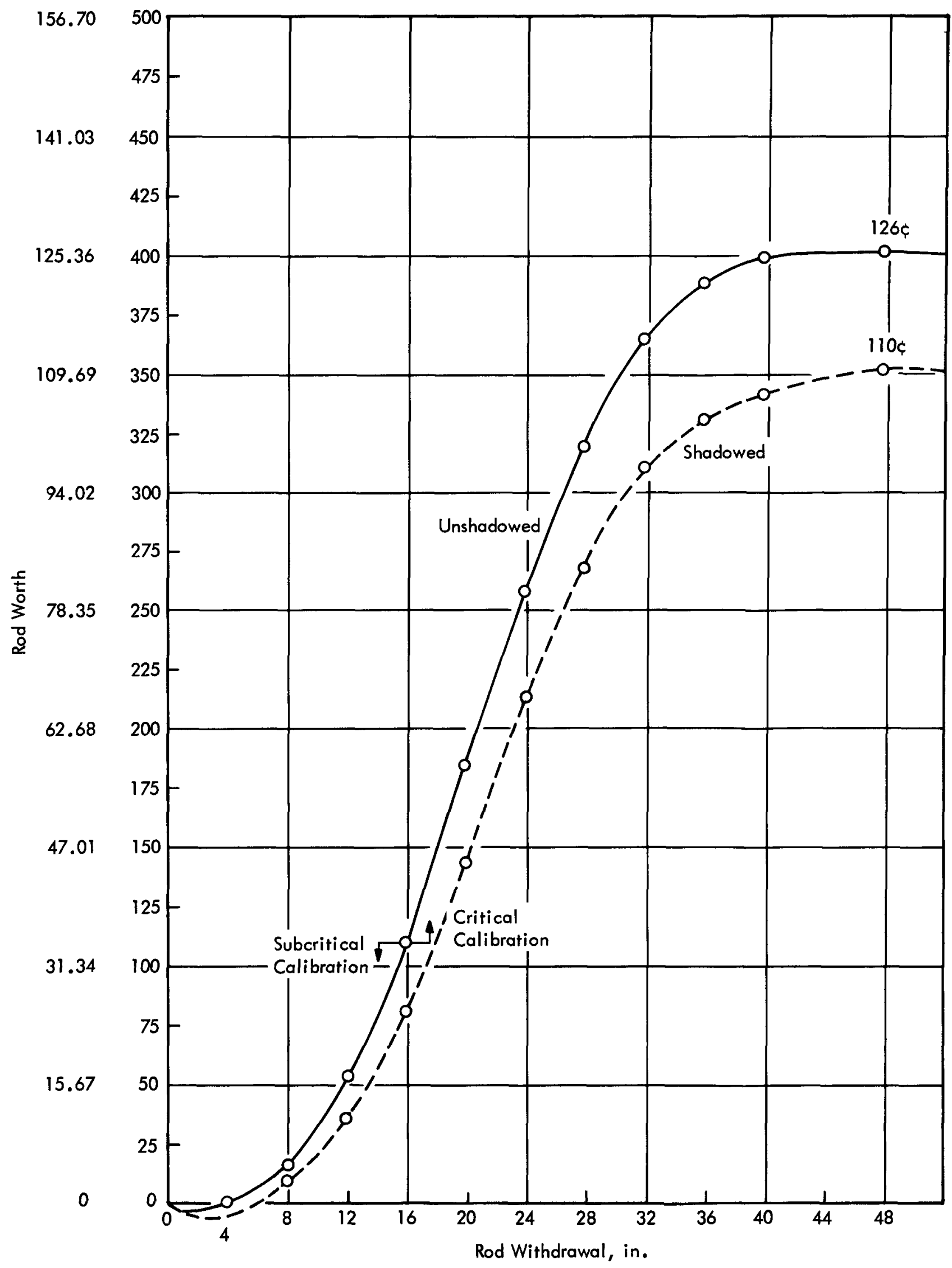

FIG.9 CALIBRATION OF NO. 1 SAFETY ROD 


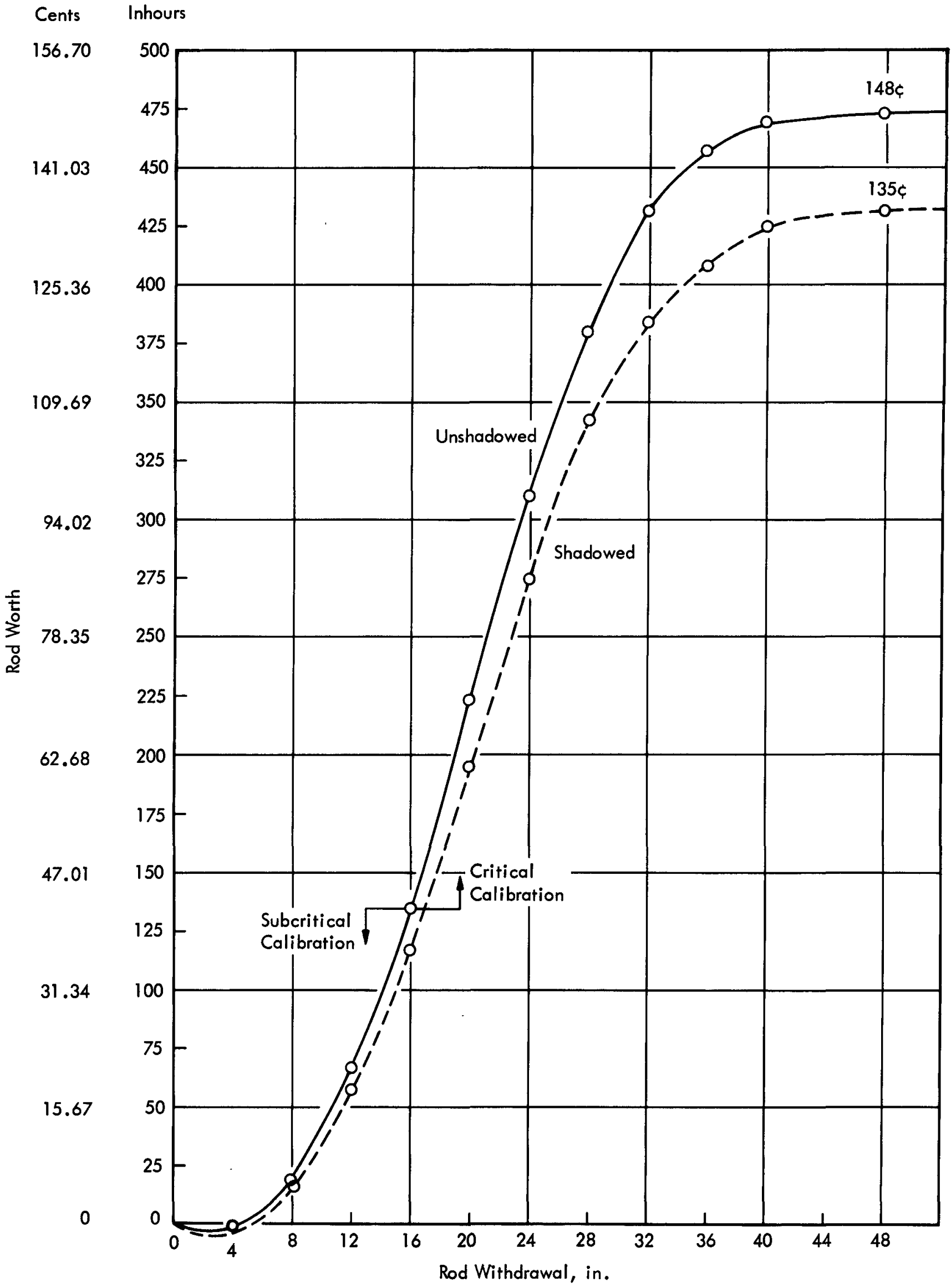

FIG.10 CALIBRATION OF NO. 2 SAFETY ROD 


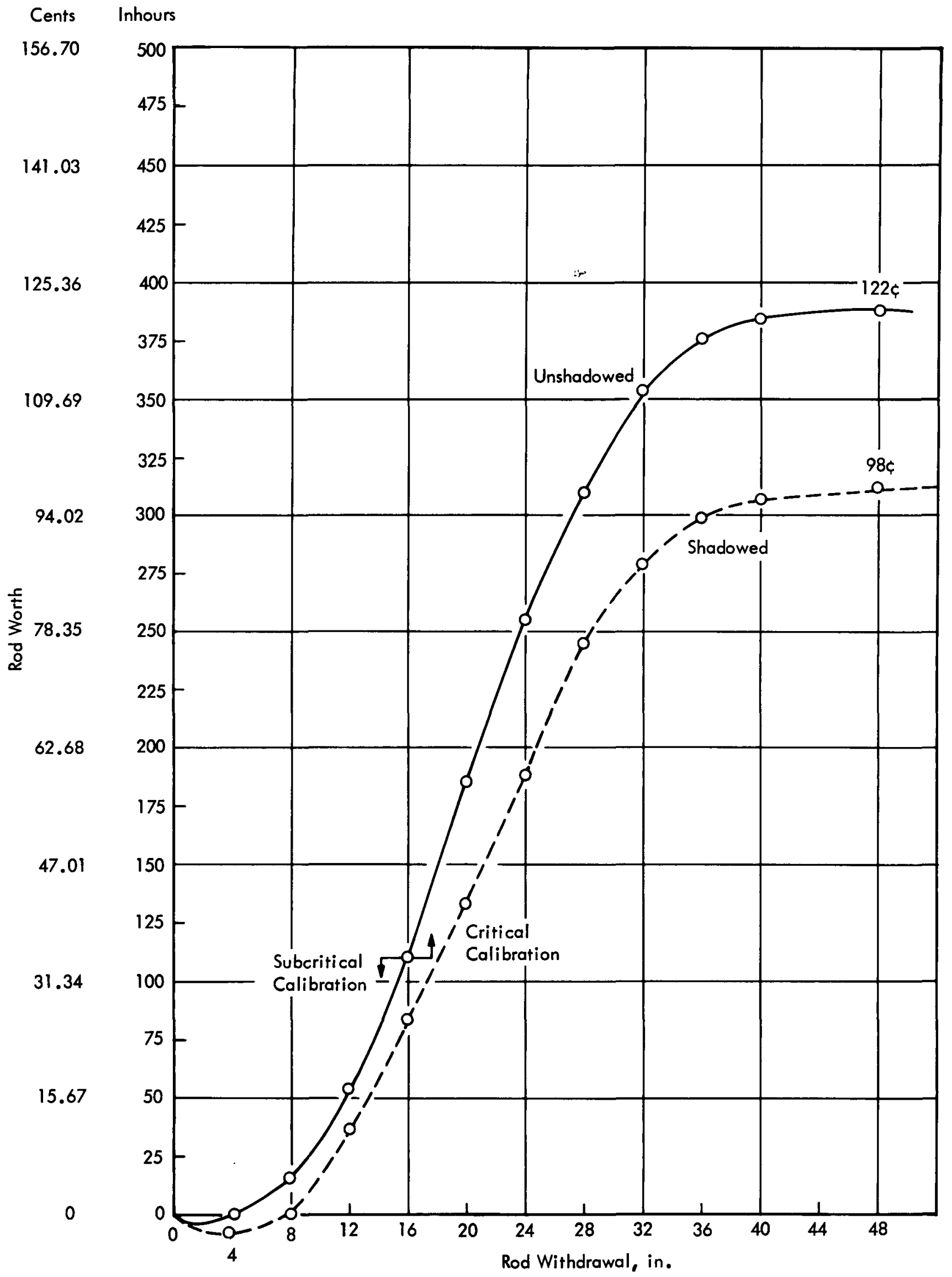

FIG. 11 CALIBRATION OF NO. 4 SAFETY ROD 
were 1.26 dollars, 1.48 dollars and 1.22 dollars, respectively, whereas the corresponding shadowed worths were 1.10 dollars, 1.35 dollars, and 98 cents. The apparent reduction in safety rod worth due to shadowing by the two adjacent rods therefore ranges from 9 per cent (rod No. 2) to 20 per cent (rod No. 4). Although no predicted rod worth curves are shown in Figs. 9 through 11 , the predicted curves have essentially the same shape as those measured, but the predicted worths are generally somewhat larger than measured. 6 This will be discussed in more detail later on.

Several points in Figs. 9 through 11 require clarification. First, all of the worth curves dip below the zero-worth line in the withdrawal range from 0 to 6 in. This behavior results from the fact that when the rods are fully inserted in the reactor, their poison section is not axially centered about the core midplane. 4 Instead, there is approximately a 3 -in. "overshoot" which results in 21 in. of the 36-in. -long poison section being below the core midplane and 15 in. above it. Therefore, during the first 3 in. of rod withdrawal required to center the poison section about the core midplane, negative reactivity is added to the reactor rather than positive reactivity. Approximately 3 in. of subsequent withdrawal is then required to overcome this initial reactivity loss, and to leave the reactor in the same mirror-image geometrical configuration, regarding poison and fuel distribution, that it had when the rod was fully inserted.

Another point to be noticed in Figs. 9, 10 and 11 is that all of the calibration curves are terminated at $48 \mathrm{in.}$ of withdrawal, whereas the full stroke of a safety rod is 54 in. (Section II-B-2). The reason for this is that no further reactivity addition was measured beyond 48 in.

The unshadowed calibration curves in Figs. 9 through 11 show the point at which the method of calibration changed from subcritical count rate measurements to critical intercalibration measurements. This was at 16 in. of withdrawal in all cases. However, a portion of the calibration between 16 in. and the next data point (20 in. ) required calculation of the degree of reactor subcriticality with the rod at 16 in., using count rate data, and also required knowledge of the retractable source worth (Section III-A-2). Since the shadowed rod worths were obtained entirely by subcritical count rate measurements, no similar designation is made on their curves.

The results of the calibrations for safety rods Nos. 1, 2 and 4 are summarized in Table 4 which also gives the predicted worths of all (eight) safety rods ${ }^{6}$ and the worths obtained in earlier rod drop testing for the seven installed rods. 3

The predicted worths were based on data obtained in the Core A critical experiment 12 ; they were modified for changes in reactor design since the time of the critical experiment. 4 The principal modifications 
TABLE 4 - SAFETY ROD CALIBRATIONS

\begin{tabular}{|c|c|c|c|c|c|c|c|c|c|}
\hline \multirow[b]{2}{*}{ Safety Rod No. } & \multicolumn{3}{|c|}{$\begin{array}{l}\text { Predicted Worth From } \\
\text { Critical Experiment } 12\end{array}$} & \multicolumn{3}{|c|}{$\begin{array}{l}\text { Measured Worth From } \\
\text { Rod Drop Tests }\end{array}$} & \multicolumn{3}{|c|}{$\begin{array}{c}\text { Measured Worth From } \\
\text { This Test }\end{array}$} \\
\hline & Unshadowed, \$ & Shadowed,\$ & $\begin{array}{c}\% \\
\text { Reduction } \\
\end{array}$ & Unshadowed,\$ & Shadowed, $\$$ & $\begin{array}{c}\% \\
\text { Reduction }\end{array}$ & Unshadowed, $\$$ & Shadowed, $\$$ & $\begin{array}{c}\% \\
\text { Reduction } \\
\end{array}$ \\
\hline 1 & 1.45 & 1.13 & 22 & 1.28 & 1.02 & 20 & 1.26 & 1.10 & 13 \\
\hline 2 & 1.65 & 1.29 & 22 & 1.46 & 1.14 & 22 & 1.48 & 1.35 & 9 \\
\hline 3 & 1.45 & 1.13 & 22 & 1.19 & $(1.04) \#$ & $(12-1 / 2) \#$ & - & - & - \\
\hline 4 & 1.34 & 1.05 & 22 & 1.20 & 1.01 & 16 & 1.22 & 0.98 & 20 \\
\hline 5 & 1.34 & 1.05 & 22 & TIT & TIT & TIT & RS & RS & RS \\
\hline 6 & 1.45 & 1.13 & 22 & 1.25 & 1.00 & 20 & - & - & - \\
\hline 7 & 1.65 & 1.29 & 22 & 1.38 & 1.08 & 22 & - & - & - \\
\hline 8 & 1.45 & 1.13 & 22 & 1.16 & $(1.02) \#$ & $(12-1 / 2) \#$ & - & - & - \\
\hline $\begin{array}{l}\text { Total Unshadowed } \\
\text { Worth, } 8 \text { Rods }\end{array}$ & 11.78 & & & $10.12 \dagger$ & & & & & \\
\hline $\begin{array}{l}\text { Total Unshadowed } \\
\text { Worth, } 7 \text { Rods }\end{array}$ & $10.44 *$ & & & 8.92 & & & & & \\
\hline
\end{tabular}

* Value with safety rod No. 5 eliminated, i.e., the position occupied by either the temporary instrument thimble (TIT) or retractable source (RS) in the later experiments.

$\dagger$ Value assuming that the worth of rod No. 5 is the same as rod No. 4.

\# Values in parenthesis for safety rods Nos. 3 and 8 are half-shadowed results. They were all that could be obtained for these rods because of the instrument thimble location in one adjacent safety rod position. 
affecting rod worth since the critical mockup were an increase in the boron10 weight per rod, and the previously mentioned decrease in fuel enrichment (increase in the core size). Although all safety rods are of identical design, their predicted worths vary somewhat due to differences in distances from the core center. The predicted worths in Table 4 are based on a uniform loading of $535 \mathrm{~g}$ of boron-10 per rod.

The safety rod drop test results reported in Table 4 were obtained by measuring the neutron flux decay when rods were dropped into the core. This was done with the reactor operating at a low initial critical power level. The subcritical flux decay as a function of time after scram could then be analyzed to obtain reactivity as a function of time and, hence, the rod worth. 3 The unshadowed rod worths were determined by dropping rods singly into the core, and the shadowed worths were found by dropping rods together in two- and three-rod clusters.

Table 4 shows that the unshadowed worths measured in this test agreed very closely with the corresponding results from the rod drop tests. The agreement between the two sets of results was within approximately 1-1/2 per cent and it confirmed the validity of the rod drop worths. It was therefore concluded that it would be unnecessary to repeat the calibrations for the remaining four safety rods in this test, since the rod drop test results could be used.

Table 4 also shows that the measured unshadowed safety rod worths were somewhat less than predicted. The discrepancy varied from rod to rod but the average measured value of 1.27 dollars was about 15 per cent less than predicted. In no case, however, were any of the unshadowed worths less than 1.00 dollar. Therefore, they were well within the limits of the design specifications.

A partial explanation for the differences between measured and predicted unshadowed worths, and for the several instances in Table 4 where symmetrical rods have different measured worths, is that the as built safety rods do not have a uniform boron-10 loading of $535 \mathrm{~g}$ per rod, as designed. Investigations have shown that safety rods Nos, $1,2,3$ and 8 contain only $507 \mathrm{~g}$ of $\mathrm{B}-10$, while rods Nos. 4, 5, 6 and 7 have a $546-\mathrm{g}$ loading. 3

The shadowed safety rod worths given in Table 4 are inconsistent. The rod worth reduction due to shadowing measured in this test varied be tween rods, and it was less than predicted, averaging about 14 per cent; the shadowing effect from the rod drop tests was 22 per cent for all rods, in excellent agreement with predictions. The question therefore arose as to which set of results was correct. 
The interpretation which has been given to the safety rod shadowing results is that the shadowing effect measured in this test was too small, i. e., the shadowed worths obtained were too large. The rod drop results are considered to be more accurate. It is believed that errors were introduced in the measurements of shadowed rod worth because initially, with the rod under test and two adjacent safety rods fully inserted, the degree of reactor subcriticality was large, approximately 3.00 dollars (Section III-A -2). This is at or beyond the limit for accurate subcritical count rate analysis, using simple subcritical multiplication theory (Section IV-B). In this situation, it appears that the method tends to give reactivity changes which are larger than those which actually occur. This point will be illus trated more clearly below when the results of the ganged safety rod worth measurements are given. They were made with the reactor very far-subcritical over most of the withdrawal distance. The reduction in rod worth due to shadowing obtained from the rod drop tests, 22 per cent, has therefore been accepted as the correct value.

\section{Ganged Calibration}

The results of the ganged safety rod calibration are shown in Fig. 12. The ganged worth obtained for the seven installed rods was 9.85 dollars. The curve was found to be flat beyond 48 -in. withdrawal. The two subcritical stop points for ganged rod withdrawal, shown in Fig. 12, were also calibrated. The reactivity increment obtained between the first and second stops, and between the second stop and full withdrawal, was 25.10 cents in both cases. 


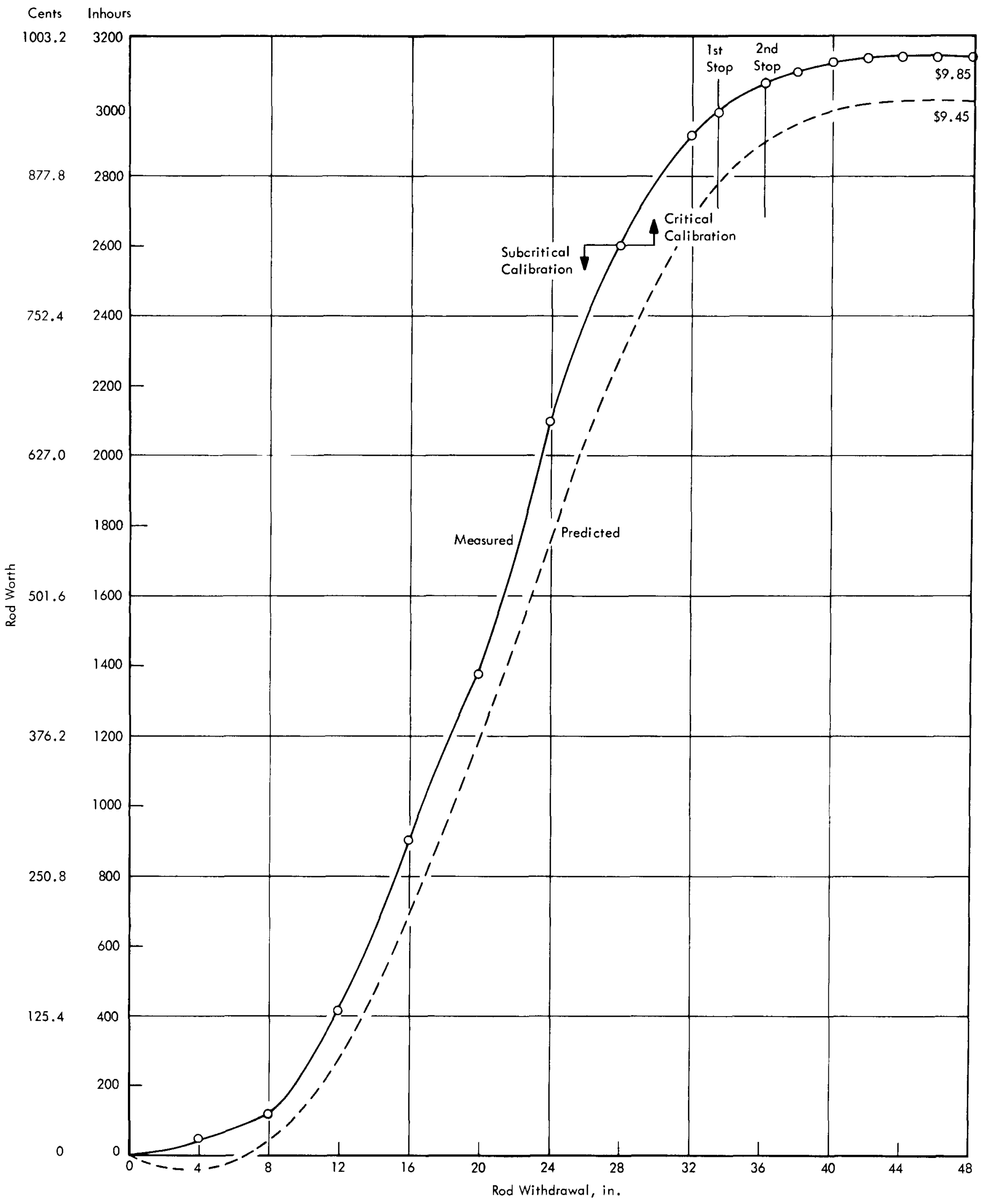

FIG.12 GANGED SAFETY ROD CALIBRATION (7 RODS) 
The predicted ganged rod calibration curve is shown by the dotted line in Fig. 12. It is based on critical experiment data.* The general shape of the predicted curve, its worth of 9.45 dollars, and the subcritical stop reactivities are in close agreement with the measurements; this was unexpected and is inconsistent with the data obtained earlier on individual rod worth.

Most of the ganged rod calibration was obtained by subcritical count rate reactivity measurements. This is indicated by the arrows in Fig. 12. Only the last $\sim 80$ cents of the calibration (beyond $28-$ in. with drawal) was made by critical intercalibration with the control rods. Also,

* In the Core A critical experiment, calibration of the ganged safety rods could not be made by means of simultaneous withdrawal of all (eight) rods. This was because of the excess reactivity limitations of the mockup. 12 However, each of the individual unshadowed safety rod worths was obtained, as well as the shadowing effect of the two adjacent rods on each rod in the array (Table 4). These data were used to calculate the total ganged rod worth. It was assumed that the ganged rod worth curve would have the same shape as measured for an individual shadowed rod. 6

This same procedure was used to predict the results of this test, 14 shown in Fig. 12, allowing for the fact that safety rod No. 5 had been replaced by the retractable source. To do this, it was reasoned that during ganged rod withdrawal, safety rods Nos. 1, 2, 4, 6 and 7 would be shadowed by two adjacent rods, and rods Nos. 3 and 8 , adjacent to the source, by only one. Furthermore, allowance was made for the fact that the 22 per cent reduction in rod worth due to shadowing measured in the critical experiment actually represented the total effect of the mutual coupling between adjacent rods (see Section V-A-1). Since three rods were involved in the shadowed measurements, and the centrally located one acted on each of the two adjacent rods and they on it, the shadowing effect of one rod on another was taken to be one-fourth of 22 per cent or 5-1/2 per cent. On this basis, the reductions in the individual unshadowed rod worths for seven ganged rod withdrawal predictions were 11 per cent and 5-1/2 per cent, respectively, in the case of the five fully-shadowed and two half-shadowed rods. Thus,

Predicted ganged worth $(7$ rods $)=0.89 \sum_{i=1,2,4}^{6,7} w_{\mu s_{i}}+0.945 \sum_{i=3,8} w_{\mu s}$

where,

$=9.45$ dollars

$\mathrm{W}_{\mu s_{i}}=$ unshadowed rod worth from critical experiment of rod $i$ 
similar to the unshadowed individual rod calibrations, a portion of the calibration between 28 -in. and 32 -in. withdrawal involved calculation of the reactor subcriticality at $28 \mathrm{in}$. and knowledge of the retractable source worth.

The curve of measured ganged rod worth does not show the dip below zero-worth in the initial part of the rod withdrawal which was predicted and which was seen in the individual rod calibrations.

There is an obvious inconsistency in the results of the ganged rod worth found in this test. The inconsistency is the fact that while the meas ured ganged worth, 9.85 dollars, is 4.2 per cent larger than the predicted value of 9.45 dollars, the individual unshadowed rod worths measured earlier averaged 15 per cent less than predicted, and the measured shadowing effect agreed with predictions. On the basis of the latter results, it would be expected that the measured ganged worth would also be 15 per cent less than predicted. For example, if the individual unshadowed rod worths from this test and the rod drop test (Table 4) are used in Eq. (4) to calculate a sevenrod ganged worth, a value of 8.07 dollars is obtained. This is 15 per cent less than predicted and it is also in close agreement with a seven-rod ganged worth value of 8.00 dollars found in the rod drop tests. 3

The conclusion reached is that the ganged worth measured in this test is apparently in error and too large by approximately 19 per cent. The best seven-rod value is therefore about 8.00 dollars. If all (eight) rods were installed, similar analysis using Eq. (4) with 11 per cent shadowing for all rods, and using the experimental worths in Table 4, gives a value of 9. 01 dollars for the eight-rod ganged worth.

The reason for the ganged calibration error is believed to be the same as discussed earlier in explaining the individual shadowed safety rod results. It is believed that errors were introduced because the major part of the calibration was calculated from simple subcritical multiplication theory, using count rate data obtained when the reactor was far-subcritical. The actual situation at the degree of subcriticality used is far more complex than allowed for in the simple theory. Larger discrepancies no doubt existed in the case of the ganged calibration than for the individual shadowed rod measurements.

The subcritical stop reactivity increments, 25.10 cents in each case, agree very closely with the predicted values of 25.0 cents. This was expected since the stops occur at the upper end of the rod travel. Their calibration was therefore made with the reactor critical by intercalibration measurements. These are considered to be much more accurate than the calibration by subcritical methods utilized over the major portion of the ganged rod withdrawal. 
The stop reactivities a re not in close agreement with the values of 32 cents and 33 cents, which must be used under the normal rod withdrawal sequence in the approach to criticality, to correctly predict from count rate data the critical control rod positions with the safety rods fully withdrawn. ${ }^{15}$ This may be due to the fact that during ganged safety rod withdrawal, the shadowing effect of the safety rods on the neutron detectors located outside the reactor vessel and above the core midplane is constantly changing. If this effect were large it would produce a change in flux at the detectors which is not directly proportional to the change in multiplication. The 32- and 33-cent values can therefore be regarded as empirical values which correctly predict the critical rod positions during normal rod withdrawal using simple subcritical multiplication theory. The actual reactivity increments are probably closer to 25 cents, however.

A similar shadowing effect during single rod withdrawal would be minimal. Therefore, the individual safety rod calibrations obtained by subcritical count rate measurements could not have been similarly effected. 
-

,

列 


\section{CONCLUSIONS AND RECOMMENDATIONS}

Accurate calibrations of the control and safety rods were obtained for various degrees of shadowing. In general, the rod worths found were somewhat less than had been predicted from critical experiment data. However, the differences can largely be accounted for by subsequent changes in the core and rod design.

Based on the experience gained in conducting the experiment, the following recommendations are offered:

- The control rod experiment could be shortened considerably without detracting from the utility or accuracy of the results. The measured shadowing effect between the rods was small enough that, for all practical purposes, the investigations of intermediate shadowing could have been eliminated. Also, the differences in the positive period and subcritical count rate results were very small; it would have been adequate to calibrate the two control rods entirely by the subcritical count rate method. If the latter had been done, only one fuel loading would have been necessary, and the calibration measurements for both rods could have been completed in one day.

- The safety rod calibrations made by rod drop measurements are considered to be more accurate than those made almost entirely by subcritical counting techniques. The accuracy of the data using the latter techniques was generally not satisfactory; only the individual unshadowed rod calibrations appeared to be sufficiently accurate, due to the small degree of reactor subcriticality at the time of the measurements. Therefore, it is recommended that rod drop measurements be used for future safety rod calibrations. 
- 


\section{REFERENCES}

1. Mueller, R. E., et al, "Initial Loading to Criticality of the Enrico Fermi Reactor", APDA-NTS-1, May 1964.

2. Mueller, R. E., et al, "Determination of Control Rod Float in the Enrico Fermi Reactor", APDA-NTS-2, November 1964.

3. Horne, R. E., et al, "Determination of the Safety Rod Drop Time in the Enrico Fermi Reactor", APDA-NTS-3, January 1965.

4. "Technical Information and Hazards Summary Report, Enrico Fermi Atomic Power Plant", Vols. 1-7, Power Reactor Development Co., Revised, March 1964.

5. Branyan, C. E., "Enrico Fermi Nuclear Test Procedure No. 6, Calibration of Shim and Regulating Rods", APDA-NTP-6, December 1963.

6. Branyan, C. E., "Enrico Fermi Nuclear Test Procedure No. 7, Safety Rod Calibration", APDA-NTP-7, June 1963.

7. Seeley, G. T., et al, "Measurement of Some Reactivity Effects in the Enrico Fermi Reactor", APDA-NTS-12, November 1967.

8. Horne, R. E., "Enrico Fermi Nuclear Test Procedure No. 14, General Reactivity Measurements", APDA-NTP-14, July 1962.

9. Mueller, R. E. , et al, "Investigation of Core Reproducibility of the Enrico Fermi Reactor", APDA-NTS-4, April 1965.

10. Wilber, H. A., et al, "Measurement of the Isothermal Temperature Coefficient of Reactivity of the Enrico Fermi Reactor", APDA-NTS-5, June 1965.

11. Mueller, R. E., "Source Multiplication Near Critica1", APDA Inter nal Memorandum, RSA-61-305, October 1961.

12. Branyan, C. E., "Core A Critical Studies for the Enrico Fermi Atomic Power Plant on ZPR-III", ANL-6629, October 1962.

13. Mueller, R. E., "Preliminary Evaluation of NTP-13, Reload for Retractable Source", APDA Internal Memorandum, October 1963. 